Check for updates

Cite this: RSC Adv., 2017, 7, 31866

Received 21st February 2017

Accepted 31st May 2017

DOI: $10.1039 / c 7 r a 02142 a$

rsc.li/rsc-advances

\section{Novel thiohydantoin analogues bearing the 1-hydroxyl-2,2,2-trifluoro-1-ethyl moiety as androgen receptor inhibitors for the potential treatment of castration resistant prostate cancer}

\author{
Yingwei Wang, (D) $t^{\mathrm{ab}}$ Yufang Deng,,$^{\mathrm{a}}$ Xuehai Pang, ${ }^{\mathrm{b}}$ Jiang Yu, ${ }^{\mathrm{a}}$ Lei Fan, ${ }^{\mathrm{c}}$ \\ Yuanwei Chen (D) *abc and Lifeng Zhao*d
}

\begin{abstract}
Enzalutamide (ENT) is an approved drug for the treatment of castration resistant prostate cancer (CRPC). Despite its success, the duration of response in patients is still limited with drug resistance. More robust CRPC drugs with novel structural motifs are urgently needed. Here, we designed and synthesized a series of 1-hydroxyl or 1-amino-2,2,2-trifluoro-1-ethyl compounds as isosteres to replace the amide group of ENT. Among the compounds prepared and tested, compund 13b is 2-fold more potent than ENT against LNCaP-AR cells. Western blot analysis showed that 13b dose-dependently inhibits the expression of the prostate-specific antigen (PSA). Further in vivo efficacy studies established that 13b has anti-tumor activity with oral administration at $15 \mathrm{mg} \mathrm{kg}^{-1}$ once daily.
\end{abstract}

\section{Introduction}

Prostate cancer is the most commonly diagnosed cancer and the third-leading cause of cancer deaths in men. ${ }^{1}$ Although approximately $75 \%$ of these patients will be cured by surgery or radiation when cancer remains within the prostate, the remainder will inevitably progress to a state of metastatic prostate cancer. ${ }^{2}$ Androgen deprivation therapy or other combination therapy, through lowering serum testosterone or competitively blocking the binding of androgens to the androgen receptor (AR), are initially effective in $90 \%$ of patients at this stage. ${ }^{3}$ Nevertheless, the vast majority of these patients will eventually develop metastatic castration resistant prostate cancer (CRPC) after long term treatments. ${ }^{4-6}$ Recent research efforts have indicated that CRPC growth is driven by AR signaling as well. ${ }^{7}$ Furthermore, many possible mechanisms influencing AR signaling have been suggested for the acquired resistance, among which AR mutations, androgen synthesis by prostate cancer cells, and over-expression

${ }^{a}$ Lab of YW Chen, Cancer Center, West China Hospital, Sichuan University and Collaborative Innovation Center, Chengdu, 610041, China. E-mail: ywchen@scu. edu.cn; Fax: +860288598 0460; Tel: +8602885980460

${ }^{b}$ Chengdu Institute of Organic Chemistry, Chinese Academy of Sciences, Chengdu, 610041, China

'Hinova Pharmaceuticals Inc., Suite 402, Building B, \#5 South KeYuan Road, Chengdu, 610041, China

${ }^{d}$ Chengdu University, Sichuan Industrial Institute of Antibiotics, Chengdu, 610041, China. E-mail: lifengzhao@scu.edu.cn; Fax: +86028 8505 8465; Tel: +86 1588241 1095

$\dagger$ Electronic supplementary information (ESI) available. See DOI: 10.1039/c7ra02142a

\$ These authors contributed equally. of $\mathrm{AR}$ or AR co-activators have been found to directly or indirectly render AR more sensitive to low androgen concentrations or sometimes turn antagonist responses to agonistic. ${ }^{8}$

Enzalutamide (ENT) was approved by FDA in 2012 for the treatment of CRPC. Unlike the first-generation AR inhibitors, such as flutamide, nilutamide, and bicalutamide (Fig. 1), ENT not only binds to AR, but also reduces nuclear translocation of AR and impairs AR binding to DNA. ${ }^{9}$ In addition, further studies suggested that ENT possesses a higher binding affinity of AR than the first-generation AR inhibitors. Clinical studies also demonstrated unequivocally its survival benefit in men with CRPC. ${ }^{10,11}$ Despite its success, the duration of response in patients is still limited. Recently, AR with a specific mutation (F876L) was identified to confer resistance to ENT. ${ }^{\mathbf{1 2}}$ This disappointing outlook suggests that better compounds with novel structure motif need to be developed urgently.
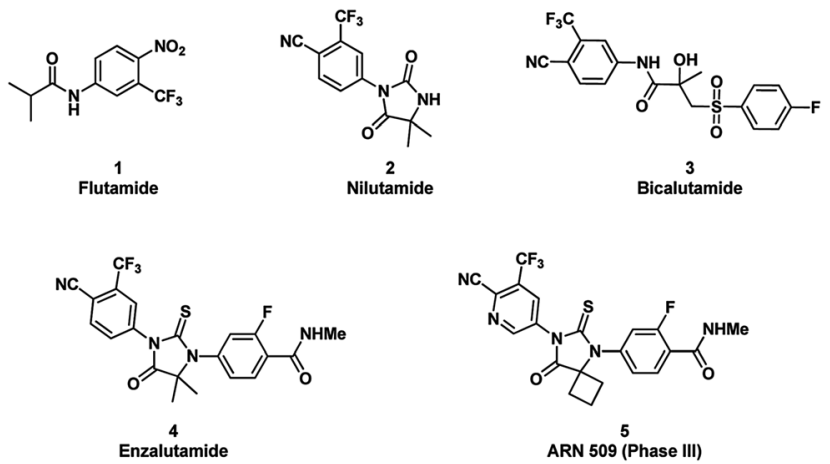

Fig. 1 The first and second generation AR inhibitors. 

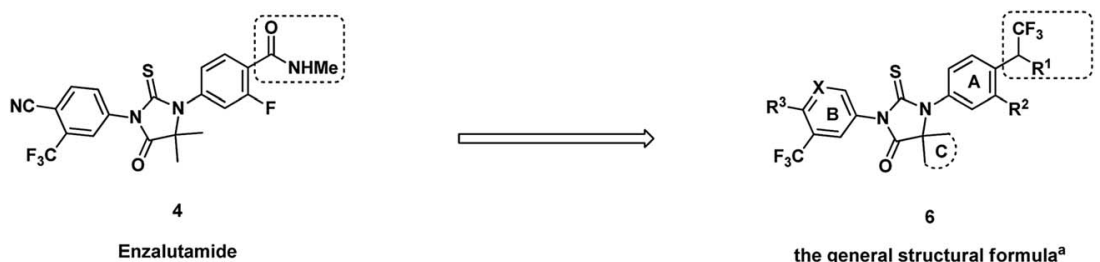

the general structural formula ${ }^{a}$

${ }^{\text {a }} \mathrm{X}=\mathrm{N}, \mathrm{C} ; \mathrm{R}^{1}=$ hydrophilic group; $\mathrm{R}^{2}=\mathrm{F}, \mathrm{H} ; \mathrm{R}^{3}=\mathrm{CN}, \mathrm{COOH}, \mathrm{CONH}_{2}, \mathrm{C}=$ alicyclic ring.

Fig. 2 Proposed novel structure as potential AR inhibitors.

Replacement of amide group by other isosteres is a common practice in medicinal chemistry effort. Black and his colleagues from Merck reported to use trifluoroethylamine group as the isostere of amide in their searching of novel cathepsin $\mathrm{K}$ inhibitors. ${ }^{13}$ After replacement of amide with trifluoroethylamine, the potency and selectivity were improved, also the new function group are stable for P1-P2 cleavage that was observed for other amide inhibitors. Considering the major metabolic path way of ENT is through $N$-demthylation and amide hydrolysis, ${ }^{14,15}$ a series of isosteres analogs bearing trifluoroethylamine or trifluoroethanol were prepared as novel AR inhibitors. At the same time, C-ring was also optimized for potentially improvement of drug resistance (Fig. 2). Here we report our progress and also the in vivo and in vitro data of compound 13b which is dose-dependently inhibiting expression of prostatespecific antigen and has anti-tumor activity at oral administration dose of $15 \mathrm{mg} \mathrm{kg}^{-1}$ once daily.

\section{Results and discussion}

\subsection{Chemistry}

Synthetic routes of evaluated compounds 13a-f were depicted in Scheme 1 as path A and path B, respectively. In path A, compounds 8a-d was obtained by coupling of bromide $\mathbf{7 a - b}$ with the appropriated amino-acid under Ullmann coupling reaction conditions. Then, compounds 8a-d were directly subjected to esterification without further purification to afford compounds 9a-d under conditions of $\mathrm{K}_{2} \mathrm{CO}_{3}$ and $\mathrm{CH}_{3}$ I. Finally, compounds 13a-f were obtained through the reaction between $\mathbf{9 a - d}$ and 10a-b.

In path $\mathrm{B}$, the starting material 11a-b were provided from corresponding benzaldehyde according the reported procedure. ${ }^{15}$ Compounds 12a-d, then, were prepared under Strecker reaction conditions using compounds 11a-b, TMSCN and corresponding ketone as substrates. Finally, compounds $\mathbf{1 3} \mathbf{g}-\mathbf{j}$ were obtained by reacting 12a-d with 10b. Other analogues, 14a-d and 15a-i, were synthesized form 13a-b by substitution, alkylation, oxidation, or hydrolysis reaction as shown in Scheme 2.

\subsection{Biology activity}

The in vitro anti-proliferation activities were evaluated by using LNCaP/AR cells (prostate cancer cells overexpressing AR). In order to mimic the CRPC state, the cells were cultured in charcoal stripped serum and treated with compounds for 6 days. The results were summarized in Tables 1,2 and 3.

The hydroxyl trifluoroethyl analog compound 13a, was first prepared because of its easily synthesis, showed $0.38 \mu \mathrm{M}$ activity
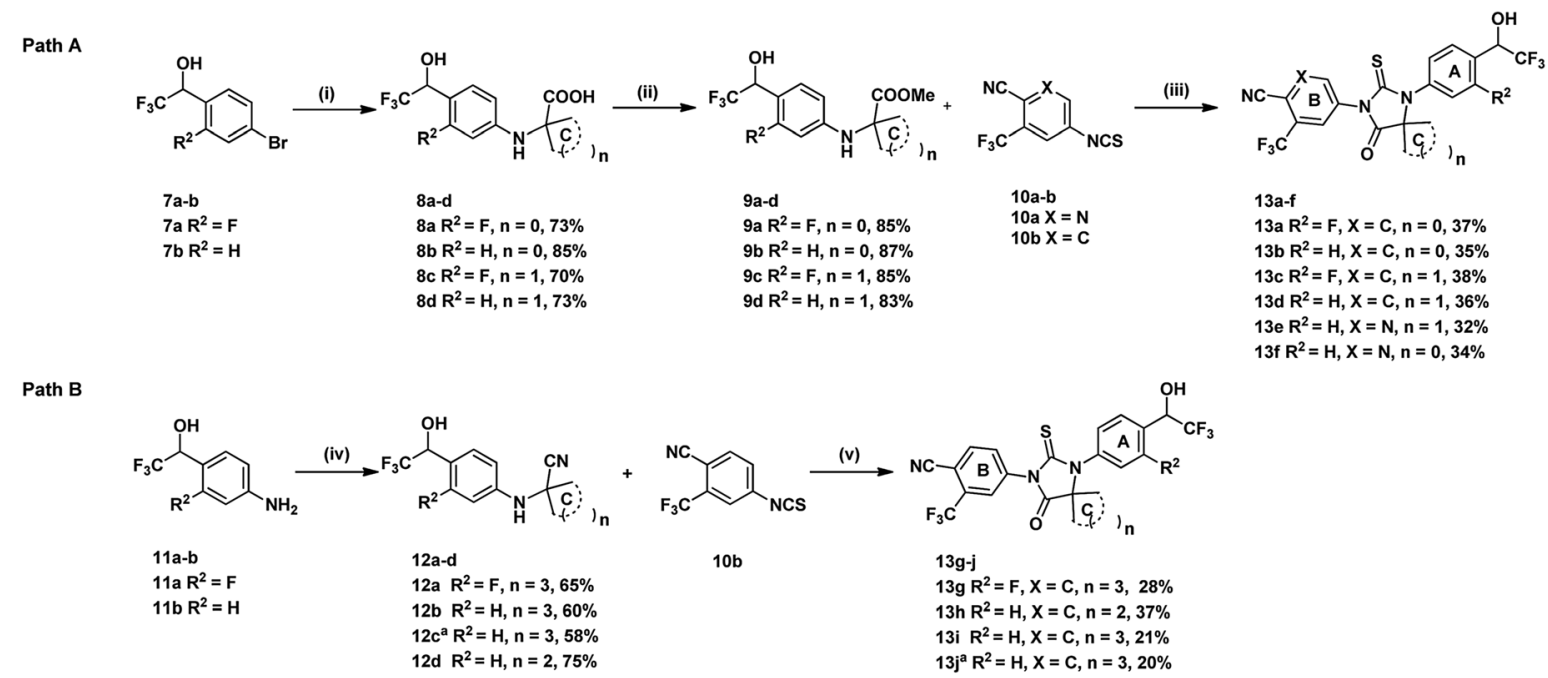

${ }^{a}$ The $C$ ring of compounds $12 \mathrm{c}$ and $13 \mathrm{j}$ is 3,3-dimethylcyclohexane.

Scheme 1 Reagents and conditions: (i) $10 \% \mathrm{Cul}, 2 \% \mathrm{Cu}, 20 \% \mathrm{~N}, \mathrm{~N}$-dimethylglycine as ligand, $\mathrm{K}_{2} \mathrm{CO}_{3}$, amino-acid, $\mathrm{DMF}, 80{ }^{\circ} \mathrm{C}$; (ii) $\mathrm{K}_{2} \mathrm{CO}_{3}, \mathrm{CH}_{3} \mathrm{l}$, DMF, rt; (iii) $10 \mathrm{a}$ or $10 \mathrm{~b}, \mathrm{DMAc}, 80^{\circ} \mathrm{C}, 24 \mathrm{~h}$; (iv) TMSCN, $\mathrm{AcOH}$, ketone, reflux; (v) $10 \mathrm{~b}, \mathrm{DMAc}, 80^{\circ} \mathrm{C}, 24 \mathrm{~h}$, then $\mathrm{MeOH}$ and $1 \mathrm{~N} \mathrm{HCl}$, reflux. 


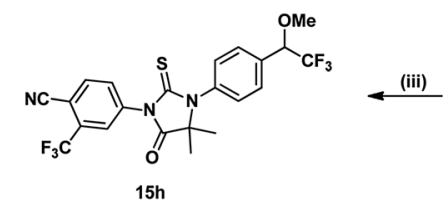

$15 \mathrm{~h}$

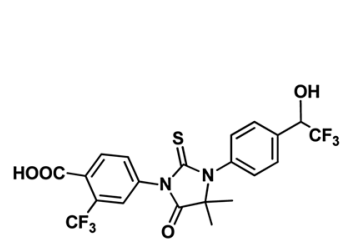

$15 f$<smiles>C1CCCC1</smiles>

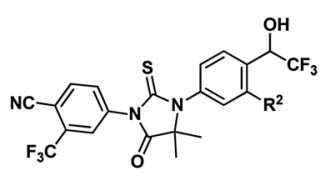

$13 a$ or $b$<smiles>[R2]c1cc(N2C(=S)N(c3ccc(C#N)c(C(F)(F)F)c3)C(=O)C2(C)C)ccc1C([R])C(C)(C)C(C)(C)C</smiles>

14a-d and 15a-e
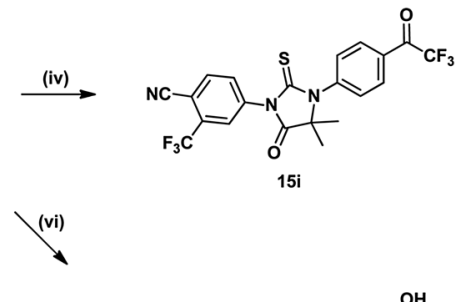

Scheme 2 Reagents and conditions: (i) $\mathrm{Et}{ }_{3} \mathrm{~N}, \mathrm{MsCl}, \mathrm{DCM}, 0{ }^{\circ} \mathrm{C}, 2 \mathrm{~h}$; (ii) amino or amino alcohol in THF, reflux, 12 h; (iii) $\mathrm{NaH}, \mathrm{Mel}, \mathrm{DMF}, \mathrm{rt}$; (iv) IBX, DMSO, rt, $12 \mathrm{~h}$; (v) $\mathrm{H}_{2} \mathrm{SO}_{4}, 100{ }^{\circ} \mathrm{C}, 24 \mathrm{~h}$; (vi) $4 \mathrm{~N} \mathrm{NaOH}, 30 \% \mathrm{H}_{2} \mathrm{O}_{2}, \mathrm{DMSO}, 0{ }^{\circ} \mathrm{C}, 40 \mathrm{~min}$.

against LNCaP-AR cells compared with ENT of $0.25 \mu \mathrm{M}$. Encourage by this result, C-ring analogs of cyclobutyl 13c and cyclohexyl 13g were also prepared and achieved sub- $\mu \mathrm{M}$ activity. However, to our surprise, the closest isostere of amide, $\mathrm{N}$ methylamino trifluoroethyl analog 14a lost the activity by 10fold. Considering the poor solubility of ENT, more hydroxyl groups were introduced. To our delight, compounds $\mathbf{1 4 b}, \mathbf{1 4 c}$ and $14 \mathrm{~d}$ were also expressed good activity with $\mathrm{IC}_{50}$ from 0.35 to $0.92 \mu \mathrm{M}$.

Table 1 In vitro anti-proliferative activity $\left(\mathrm{IC}_{50} \mu \mathrm{M}\right)$ of compounds against LNCaP-AR cell ${ }^{a}$

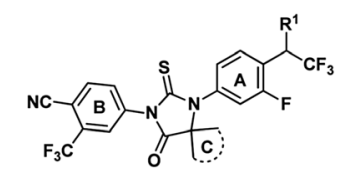

\begin{tabular}{|c|c|c|c|}
\hline ID & $\mathrm{R}^{1}$ & $\mathrm{C}$ & $\mathrm{IC}_{50}(\mu \mathrm{M})$ \\
\hline ENT & - & - & 0.25 \\
\hline $13 a$ & & & 0.38 \\
\hline $14 a$ & & & 2.52 \\
\hline $14 b$ & & & 0.35 \\
\hline $14 \mathrm{c}$ & & & 0.64 \\
\hline 14d & & & 0.92 \\
\hline $13 c$ & & & 0.86 \\
\hline $13 g$ & & & 0.98 \\
\hline
\end{tabular}

${ }^{a} \mathrm{IC}_{50}$ was average of three determinations and deviation from the average was $<5 \%$ of average value.
Analogues with unsubstituted aromatic A-ring were also prepared in order to further study SAR (Table 2). Compound 13b represented an approximate 2-fold improvement over ENT. The second most active compound is $\mathbf{1 5 b}$, with $\mathrm{N}-\mathrm{CH}_{3}$ trifluoroethyl substitutions. Compound 15e with dihydroxyl propyl amino substitution provided $1.51 \mu \mathrm{M}$ activity against LNCaP-AR. Other compounds $15 \mathbf{a}-\mathbf{d}, \mathbf{1 5} \mathbf{h}-\mathbf{i}$ were found to have moderate to potent activities in the range of $0.15-0.83 \mu \mathrm{M}$ against LNCaP-AR cell line.

ARN-509, which has substituted pyridine as B-ring and cyclobutyl as C-ring is under phase III trial for CRPC, ${ }^{16}$ therefore modification of A-ring substitution and C-ring size were also conducted in this studies (Table 3). However, in comparison with compound 13b, expanded the ring size of C-ring (compounds 13d and $\mathbf{1 3} \mathbf{h}-\mathbf{j}$ ) was detrimental to the activity. When C-ring was cyclobutyl group and B-ring is pyridine, compound $13 \mathrm{e}$ regained activity with $\mathrm{IC}_{50}$ of $0.26 \mu \mathrm{M}$. To our

Table 2 In vitro anti-proliferative activity $\left(\mathrm{IC}_{50} \mu \mathrm{M}\right)$ of compounds against LNCaP-AR cell ${ }^{a}$

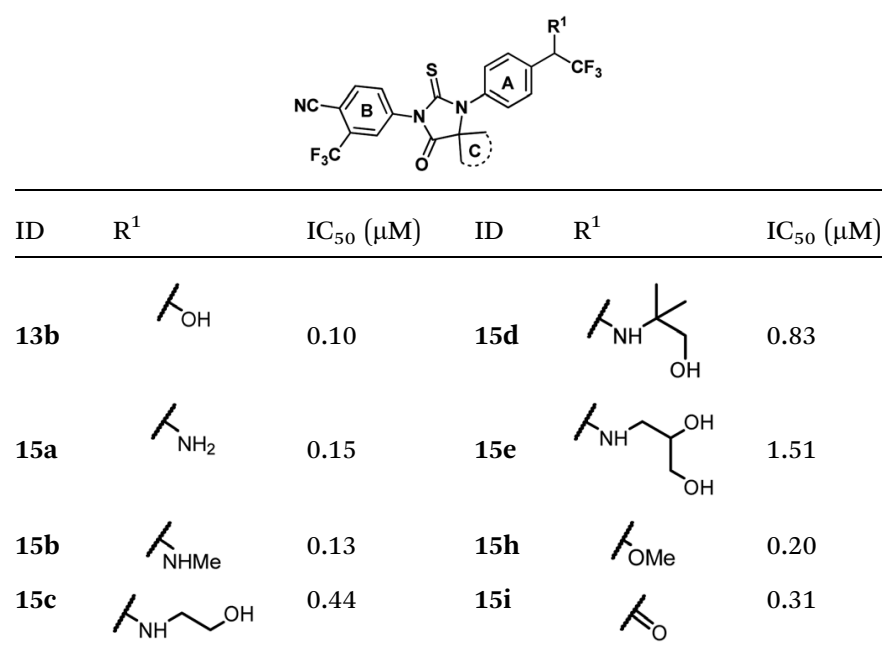

${ }^{a}$ Control compound $\left(\mathrm{IC}_{50}\right.$ of ENT is $0.25 \pm 0.01 \mu \mathrm{M}$ ) used in all assays; $\mathrm{IC}_{50}$ was average of three determinations and deviation from the average was $<5 \%$ of average value. 
Table 3 In vitro anti-proliferative activity $\left(\mathrm{IC}_{50} \mu \mathrm{M}\right)$ of compounds against LNCaP-AR cell ${ }^{a}$

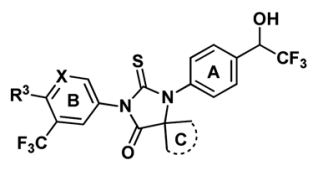

\begin{tabular}{|c|c|c|c|c|c|c|c|c|}
\hline ID & $\mathrm{X}$ & $\mathrm{R}^{3}$ & $\mathrm{IC}_{50}(\mu \mathrm{M})$ & ID & $\mathrm{C}$ & $\mathrm{x}$ & $\mathrm{R}^{3}$ & $\mathrm{IC}_{50}(\mu \mathrm{M})$ \\
\hline 13d & $\mathrm{C}$ & $\mathrm{CN}$ & 9.72 & $13 e$ & & $\mathrm{~N}$ & $\mathrm{CN}$ & 0.26 \\
\hline $13 \mathrm{~h}$ & $\mathrm{C}$ & $\mathrm{CN}$ & 8.10 & $13 f$ & & $\mathrm{~N}$ & $\mathrm{CN}$ & 5.60 \\
\hline $13 i$ & $\mathrm{C}$ & $\mathrm{CN}$ & 7.63 & $15 f$ & & $\mathrm{C}$ & $\mathrm{COOH}$ & $>10$ \\
\hline 13 & $\mathrm{C}$ & CN & 5.40 & $15 \mathrm{~g}$ & & $\mathrm{C}$ & $\mathrm{CONH}_{2}$ & 0.86 \\
\hline
\end{tabular}

${ }^{a}$ Control compound ( $\mathrm{IC}_{50}$ of ENT is $0.25 \pm 0.01 \mu \mathrm{M}$ ) used in all assays; $\mathrm{IC}_{50}$ was average of three determinations and deviation from the average was $<5 \%$ of average value.
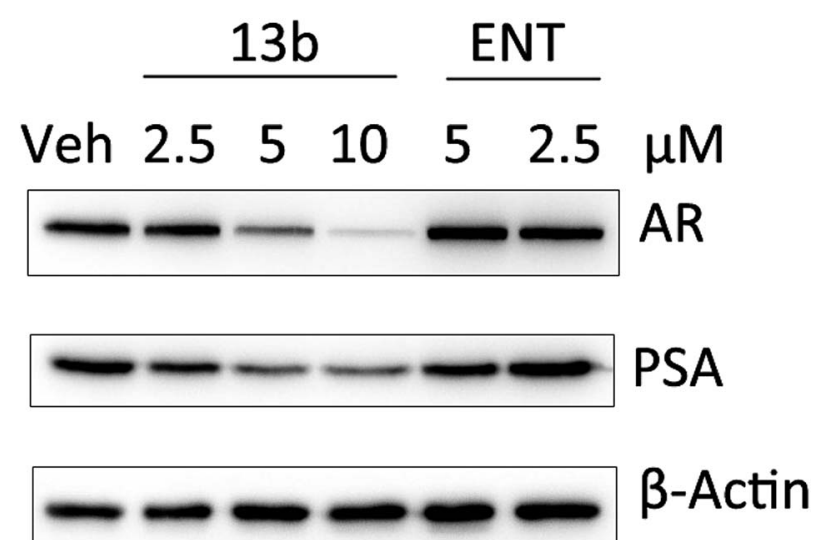

Fig. 3 Western blot analysis of PSA expression in LNCaP-AR cells.

surprise, the $\mathrm{IC}_{50}$ value of compound $\mathbf{1 3 f}$ is inferior compared with 13e. In addition, replacement of $\mathrm{CN}$ group with carboxyl group (compound 15f) totally lost activity and the carboxamide (compound 15g) retained some activity.

To test whether 13b has an effect on prostate-specific antigen (PSA) levels, compound 13b was verified in LNCaP-AR cells by Western blot analysis. The result (Fig. 3) showed that compound 13b inhibited the expression of PSA even at very low doses $(2.5 \mu \mathrm{M})$ and the inhibition activity was dose-dependent. Interestingly, the result also showed that expression of AR was down-regulated, further investigation is needed to probe the mechanism.

The in vivo anti-tumor activity of $\mathbf{1 3 b}$ was evaluated using the CPRC (LNCaP-AR) xenograft model. SCID mice were castrated and subcutaneously inoculated with LNCaP-AR cells. When the tumor volumes reached $100-200 \mathrm{~mm}^{3}$, the mice were randomly grouped (8 animals each group) and oral administrated with compound
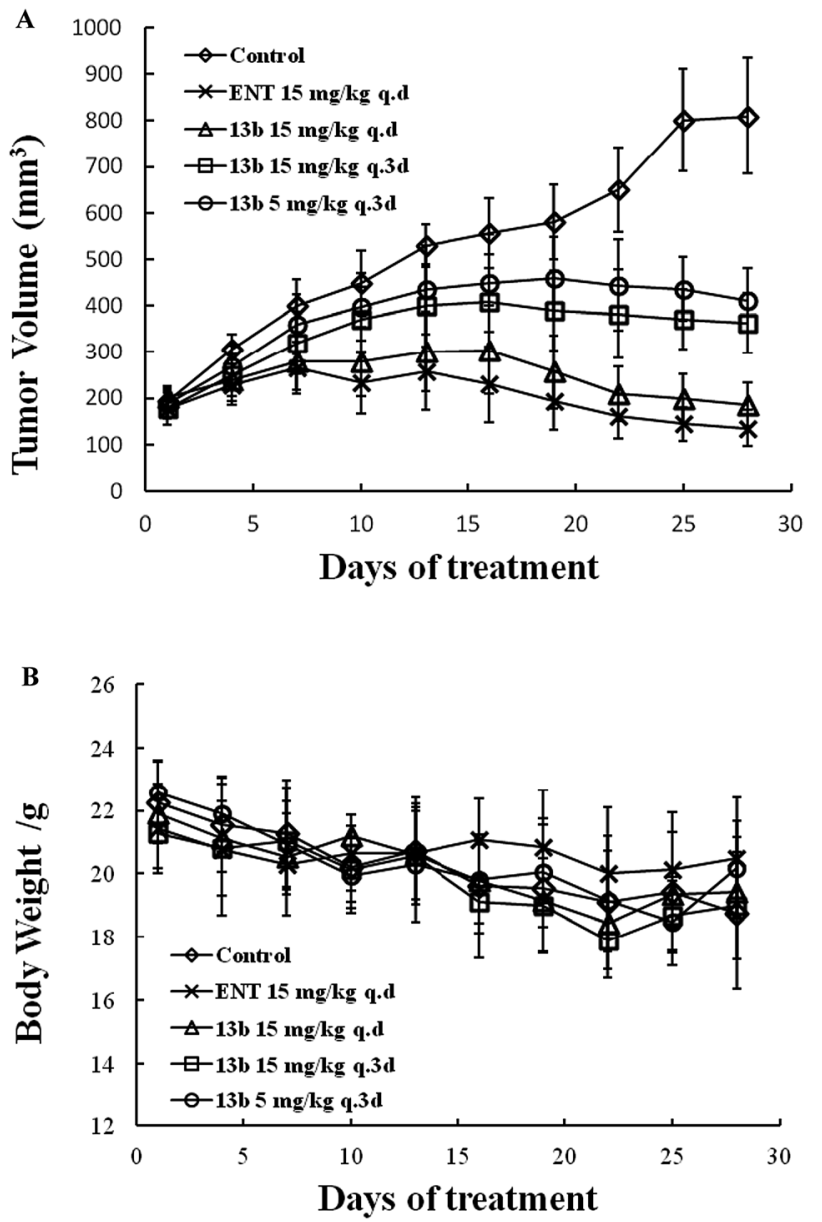

Fig. 4 Tumor volume and body weight changes of mice after oral administration of ENT and $13 \mathrm{~b}$.

13b at $15 \mathrm{mg}$ per $\mathrm{kg}$ q.d, $15 \mathrm{mg}$ per $\mathrm{kg}$ q.3d, $5 \mathrm{mg}$ per $\mathrm{kg} \mathrm{q} .3 \mathrm{~d}$, and for ENT at $15 \mathrm{mg}$ per $\mathrm{kg}$ q.d for 27 days. The tumor volumes and weight were measured every 3 days (Fig. 4). Compound $\mathbf{1 3 b}$ at all dose levels inhibited the tumor proliferation compared with the control. $5 \mathrm{mg}$ per $\mathrm{kg}$ q.3d of compound $\mathbf{1 3 b}$ have a moderate activity. $15 \mathrm{mg}$ per $\mathrm{kg}$ q.d has similar inhibition compared ENT. The tumor inhibition rate of $\mathbf{1 3 b}$ at dose of $5 \mathrm{mg}$ per $\mathrm{kg} \mathrm{q.3d}$, $15 \mathrm{mg}$ per $\mathrm{kg}$ q.3d, $15 \mathrm{mg}$ per $\mathrm{kg}$ q.d were 58.9\%, 66.0\%, 96.9\%, respectively, whereas, the ENT was more than $100 \%$ (Fig. 4a). In addition, the weight change 13b, ENT treated group and control group were slightly decreased (Fig. 4b).

\section{Conclusions}

In summary, we have synthesized a series of thiohydantoin analogues bearing substituted 2,2,2-trifluoro-1-phenylethanyl moiety. Compound 13b showed good cell activity against CRPC LNCaP-AR cell. Western blot analysis also verified compound 13b inhibited the expression of PSA in LNCaP-AR cells. Further evaluation in xenograft CRPC model showed compound $13 \mathrm{~b}$ has anti-tumor activity of $96.9 \%$ inhibition at $15 \mathrm{mg}$ per kg q.d. Further optimization and relevant works are in progress. 


\section{Experimental}

\subsection{General information}

The ${ }^{1} \mathrm{H}$ and ${ }^{13} \mathrm{C}{ }^{19} \mathrm{~F}$ NMR spectra were recorded on Avance DMX $400 \mathrm{MHz}$ NMR spectrometers (Bruker, Germany) in $\mathrm{CDCl}_{3}$ or deuterated DMSO using TMS as internal standard. Spectra are reported as follows: chemical shift $\delta$ (ppm), (integral, multiplicity ( $\mathrm{s}=$ singlet, br $\mathrm{s}=$ broad singlet, $\mathrm{d}=$ doublet, $\mathrm{dd}=$ doublet of doublets, $\mathrm{t}=$ triplet, $\mathrm{q}=$ quartet, $\mathrm{m}=$ multiplet), coupling constant $J(\mathrm{~Hz})$, assignment). ESI-HRMS spectra were recorded on a commercial apparatus and methanol was used to dissolve the sample. Reagents were purchased from commercial sources and were used as received unless mentioned otherwise. Reactions were monitored by thin layer chromatography using silica gel GF 254 plates. Column chromatography was performed on silica gel (300-400 mesh).

\subsection{Experimental section}

Compounds 9, 12, 13 were prepared by using a slightly modified literature-known procedure. ${ }^{17-20}$

General procedure for the synthesis of $9.7(1.0 \mathrm{mmol})$, amino-acid (1.2 mmol), 10\% CuI ( $0.1 \mathrm{mmol}), 2 \% \mathrm{Cu}(0.02 \mathrm{~mol})$, $20 \% \mathrm{~N}, \mathrm{~N}$-dimethylglycine $(0.2 \mathrm{mmol})$ and $\mathrm{K}_{2} \mathrm{CO}_{3}(2.0 \mathrm{mmol})$ in DMF $(15.0 \mathrm{~mL})$ was stirred at $80{ }^{\circ} \mathrm{C}$ for $24 \mathrm{~h}$, under the protection of nitrogen. After the reaction, $1 \mathrm{~N} \mathrm{HCl}$ was added to adjust the $\mathrm{PH}$ value to 3-4. Then, the solution was partitioned between ethyl acetate and water. The organic layer was concentrated to give the crude product for the flowing reaction. A stirred solution of the crude product and $\mathrm{K}_{2} \mathrm{CO}_{3}(1.0 \mathrm{mmol})$ in $\mathrm{DMF}(5 \mathrm{~mL})$ then, $\mathrm{CH}_{3} \mathrm{I}(1 \mathrm{mmol})$ was added. After the reaction, the solution was quenched with water $(25 \mathrm{~mL})$. Then, aqueous residue was extracted with EA $(20 \mathrm{~mL} \times 3)$, dried over $\mathrm{Na}_{2} \mathrm{SO}_{4}$, concentrated and purified by column chromatography (PE : EA/1 : 3) to given compounds 9 (yield from 59-76\%).

General procedure for the synthesis of 12. The mixture of 11 (1.0 mmol), TMSCN $(2.0 \mathrm{mmol})$, ketone $(4.0 \mathrm{mmol})$ and $5 \mathrm{~mL}$ AcOH was stirred in a sealed tube at $80^{\circ} \mathrm{C}$ for $24 \mathrm{~h}$. The solution was neutralized with aqueous sodium hydrogen carbonate. Then, the mixture was extracted with ethyl acetate $(20 \mathrm{~mL} \times 3)$. The combined organics were dried over $\mathrm{Na}_{2} \mathrm{SO}_{4}$, filtered, concentrated and purified by column chromatography (PE : EA/ $1: 2$ ) to give 12 (yield from $58-75 \%$ ).

General procedure for the synthesis of $13 a-f$. To the mixture of compound 9a (53 mg, $0.17 \mathrm{mmol}$ ) and compound $10 \mathrm{~b}(79 \mathrm{mg}$ $0.34 \mathrm{mmol})$ in DMAc $(10 \mathrm{~mL})$, the mixture was heated to $80{ }^{\circ} \mathrm{C}$ for $24 \mathrm{~h}$. After the reaction, water $(30 \mathrm{~mL})$ was added. The resulting mixture was extracted with ethyl acetate, washed with brine, dried over sodium sulfate, concentrated and purified by column chromatography (PE : EA/1:1) to give a brown solid as crude product, which was purified by preparative chromatography to give compound 13a as a white solid ( $32 \mathrm{mg}, 37 \%$ yield).

Compounds 13b-f were synthesized by a similar procedure as described for compound 13a.

4-(3-(3-Fluoro-4-(2,2,2-trifluoro-1-hydroxyethyl)phenyl)-4,4-dimethyl-5-oxo-2-thioxoimidazolidin-1-yl)-2-(trifluoromethyl)benzonitrile (13a). ${ }^{1} \mathrm{H} \mathrm{NMR}\left(400 \mathrm{MHz}, \mathrm{CDCl}_{3}\right) \delta 7.97(\mathrm{dd}, J=9.0$,
$4.9 \mathrm{~Hz}, 2 \mathrm{H}), 7.87-7.76(\mathrm{~m}, 2 \mathrm{H}), 7.21(\mathrm{dd}, J=8.3,1.7 \mathrm{~Hz}, 1 \mathrm{H}), 7.12$ $(\mathrm{td}, J=9.7,1.9 \mathrm{~Hz}, 1 \mathrm{H}), 5.43(\mathrm{q}, J=6.3 \mathrm{~Hz}, 1 \mathrm{H}), 3.88-3.45(\mathrm{~m}$, $1 \mathrm{H}), 1.61(\mathrm{~s}, 6 \mathrm{H}) .{ }^{13} \mathrm{C} \mathrm{NMR}\left(101 \mathrm{MHz}, \mathrm{CDCl}_{3}\right) \delta 179.85,174.78$, 160.31 (d, $J=248.6 \mathrm{~Hz}), 137.18$ (d, $J=9.2 \mathrm{~Hz}), 137.00,135.41$, $134.61(\mathrm{q}, J=33.1 \mathrm{~Hz}), 132.28,130.24(\mathrm{~d}, J=4.5 \mathrm{~Hz}), 127.15(\mathrm{q}, J$ $=4.8 \mathrm{~Hz}), 125.94(\mathrm{~d}, J=3.5 \mathrm{~Hz}), 123.93(\mathrm{q}, J=281.1 \mathrm{~Hz}), 123.81$ $(\mathrm{d}, J=13.2 \mathrm{~Hz}), 121.87(\mathrm{q}, J=283.3 \mathrm{~Hz}), 117.43(\mathrm{~d}, J=23.8 \mathrm{~Hz})$, $114.83,110.18,66.75,65.62$ (q, $J=33.5 \mathrm{~Hz}), 23.69 .{ }^{19} \mathrm{~F} \mathrm{NMR}(376$ $\left.\mathrm{MHz}, \mathrm{CDCl}_{3}\right) \delta-62.38,-78.42,-113.83$. HRMS (EI) calcd for $\mathrm{C}_{21} \mathrm{H}_{14} \mathrm{~F}_{7} \mathrm{~N}_{3} \mathrm{O}_{2} \mathrm{~S}[\mathrm{M}+\mathrm{H}]^{+}:$506.0768, found: 506.0769.

4-(4,4-Dimethyl-5-oxo-2-thioxo-3-(4-(2,2,2-trifluoro-1-hydroxyethyl)phenyl)imidazolidin-1-yl)-2-(trifluoromethyl)benzonitrile (13b). ${ }^{1} \mathrm{H}$ NMR (400 MHz, $\mathrm{CDCl}_{3}$ ) $\delta 7.98(\mathrm{~d}, J=9.2 \mathrm{~Hz}, 2 \mathrm{H}), 7.84(\mathrm{dd}, J$ $=8.3,1.6 \mathrm{~Hz}, 1 \mathrm{H}), 7.68(\mathrm{~d}, J=8.2 \mathrm{~Hz}, 2 \mathrm{H}), 7.37(\mathrm{~d}, J=8.4 \mathrm{~Hz}$, $2 \mathrm{H}), 5.28-5.02(\mathrm{~m}, 1 \mathrm{H}), 2.87(\mathrm{~s}, 1 \mathrm{H}), 1.61(\mathrm{~s}, 6 \mathrm{H}) .{ }^{13} \mathrm{C}$ NMR $(101$ $\left.\mathrm{MHz}, \mathrm{CDCl}_{3}\right) \delta 179.88,174.96,165.29,137.09,136.00,135.77$, $135.32,133.62(\mathrm{q}, J=34.1 \mathrm{~Hz}), 132.26,129.76,129.07,127.16$ (q, $J=5.1 \mathrm{~Hz}), 124.04(\mathrm{q}, J=280.1 \mathrm{~Hz}), 121.89(\mathrm{q}, J=273.3 \mathrm{~Hz})$, $114.83,110.19,71.97(\mathrm{q}, J=32.1 \mathrm{~Hz}), 66.60,23.73 .{ }^{19} \mathrm{~F}$ NMR $(376$ $\left.\mathrm{MHz}, \mathrm{CDCl}_{3}\right) \quad \delta-61.97,-78.16$. HRMS (EI) calcd for $\mathrm{C}_{21} \mathrm{H}_{15} \mathrm{~F}_{6} \mathrm{~N}_{3} \mathrm{O}_{2} \mathrm{~S}[\mathrm{M}+\mathrm{H}]^{+}:$488.0862, found: 488.0869 .

4-(5-(3-Fluoro-4-(2,2,2-trifluoro-1-hydroxyethyl)phenyl)-8-oxo-6thioxo-5, 7-diazaspiro[3.4]octan-7-yl)-2-(trifluoromethyl)benzonitrile (13c). ${ }^{1} \mathrm{H}$ NMR $\left(400 \mathrm{MHz}, \mathrm{CDCl}_{3}\right) \delta 7.98(\mathrm{dd}, J=8.4,5.0 \mathrm{~Hz}$, 2H), 7.93-7.79 (m, 2H), 7.24 (dd, $J=8.4,1.9 \mathrm{~Hz}, 1 \mathrm{H}), 7.14$ (dd, $J$ $=9.9,1.9 \mathrm{~Hz}, 1 \mathrm{H}), 5.52(\mathrm{q}, J=6.3 \mathrm{~Hz}, 1 \mathrm{H}), 2.88(\mathrm{ddd}, J=5.3,3.5$, $2.5 \mathrm{~Hz}, 1 \mathrm{H}$ ), 2.70 (ddd, $J=8.9,6.6,3.4 \mathrm{~Hz}, 2 \mathrm{H}$ ), 2.56 (ddd, $J=$ 20.0, 10.0, $2.4 \mathrm{~Hz}, 2 \mathrm{H}), 2.36-2.15$ (m, 1H), $1.83-1.64$ (m, $1 \mathrm{H}) .{ }^{13} \mathrm{C}$ NMR (101 MHz, CDCl3) $\delta$ 179.86, 174.51, 160.54 (d, $J=252.3$ $\mathrm{Hz}), 137.52$ (d, $J=9.6 \mathrm{~Hz}), 136.88,135.28,133.68$ (d, $J=33.5$ $\mathrm{Hz}), 132.11,130.39$ (d, $J=4.1 \mathrm{~Hz}), 127.04(\mathrm{q}, J=5.0 \mathrm{~Hz}), 126.43$ $(\mathrm{d}, J=3.1 \mathrm{~Hz}), 124.38(\mathrm{q}, J=280.6 \mathrm{~Hz}), 123.57(\mathrm{~d}, J=13.1 \mathrm{~Hz})$, $121.73(\mathrm{q}, J=282.6 \mathrm{~Hz}), 117.89$ (d, $J=23.4 \mathrm{~Hz}), 114.78,110.24$, $67.51,65.83$ (q, $J=32.1 \mathrm{~Hz}), 31.69,13.67 .{ }^{19} \mathrm{~F}$ NMR $(376 \mathrm{MHz}$, CDCl3) $\delta-61.98,-78.38,-113.55$. HRMS (EI) calcd for $\mathrm{C}_{22} \mathrm{H}_{14} \mathrm{~F}_{7} \mathrm{~N}_{3} \mathrm{O}_{2} \mathrm{~S}[\mathrm{M}+\mathrm{H}]^{+}:$518.0768, found: 518.0772 .

4-(8-Oxo-6-thioxo-5-(4-(2,2,2-trifluoro-1-hydroxyethyl)phenyl)5,7-diazaspiro[3.4]octan-7-yl)-2-(trifluoromethyl)benzonitri-le (13d). ${ }^{1} \mathrm{H}$ NMR $\left(400 \mathrm{MHz}, \mathrm{CDCl}_{3}\right) \delta 7.98(\mathrm{dd}, J=5.1,3.2 \mathrm{~Hz}, 2 \mathrm{H}), 7.90-$ $7.83(\mathrm{~m}, 1 \mathrm{H}), 7.74(\mathrm{t}, J=9.1 \mathrm{~Hz}, 2 \mathrm{H}), 7.43-7.34(\mathrm{~m}, 2 \mathrm{H}), 5.15(\mathrm{q}, J$ $=6.6 \mathrm{~Hz}, 1 \mathrm{H}), 3.11-2.76(\mathrm{~m}, 1 \mathrm{H}), 2.75-2.63(\mathrm{~m}, 2 \mathrm{H}), 2.64-2.50$ (m, 2H), 2.34-2.16 (m, 1H), 1.70 (dtt, $J=10.5,7.7,5.1 \mathrm{~Hz}, 1 \mathrm{H})$. ${ }^{13} \mathrm{C}$ NMR $\left(101 \mathrm{MHz}, \mathrm{CDCl}_{3}\right) \delta 179.91,174.77,137.04,136.16$, 135.72, 135.23, 133.61 (q, $J=34.1 \mathrm{~Hz}$ ), 132.16, 130.20, 129.25, 127.07 (q, $J=5.1 \mathrm{~Hz}), 124.03$ (q, $J=280.1 \mathrm{~Hz}), 121.89$ (q, $J=$ $273.3 \mathrm{~Hz}$ ), 114.84, 110.12, 72.10 (q, $J=32.1 \mathrm{~Hz}$ ), 67.45, 31.59, 13.70. ${ }^{19} \mathrm{~F} \mathrm{NMR}\left(376 \mathrm{MHz}, \mathrm{CDCl}_{3}\right) \delta-61.96,-78.09$. HRMS (EI) calcd for $\mathrm{C}_{22} \mathrm{H}_{15} \mathrm{~F}_{6} \mathrm{~N}_{3} \mathrm{O}_{2} \mathrm{~S}[\mathrm{M}+\mathrm{H}]^{+}: 500.0862$, found: 500.0866 .

5-(8-Oxo-6-thioxo-5-(4-(2,2,2-trifluoro-1-hydroxyethyl)phenyl)5,7-diazaspiro[3.4]octan-7-yl)-3-(trifluoromethyl)picolino-nitrile (13e). ${ }^{1} \mathrm{H}$ NMR (400 MHz, DMSO) $\delta 9.23(\mathrm{~s}, 1 \mathrm{H}), 8.77(\mathrm{~d}, J=$ $1.9 \mathrm{~Hz}, 1 \mathrm{H}), 7.75(\mathrm{~d}, J=8.3 \mathrm{~Hz}, 2 \mathrm{H}), 7.48(\mathrm{~d}, J=8.4 \mathrm{~Hz}, 2 \mathrm{H}), 7.03$ (s, 1H), 5.49-5.19 (m, 1H), 2.72-2.59 (m, 2H), 2.50-2.38 (m, 2H), 2.07-1.90 (m, 1H), 1.66-1.43 (m, 1H). ${ }^{13} \mathrm{C}$ NMR (101 MHz, DMSO) $\delta 180.05,174.96,154.07,137.59,136.19,136.03$ (q, $J=$ $4.2 \mathrm{~Hz}$ ), 133.82, 130.31, 129.51, 129.24 (q, $J=34.1 \mathrm{~Hz}), 129.20$ (q, $J=2.0 \mathrm{~Hz}), 125.43(\mathrm{q}, J=277.1 \mathrm{~Hz}), 122.04(\mathrm{q}, J=273.3 \mathrm{~Hz})$, 
114.73, 70.41 (q, $J=31.5 \mathrm{~Hz}), 67.98,31.49,13.86 .{ }^{19} \mathrm{~F}$ NMR $(376$ $\mathrm{MHz}$, DMSO) $\delta-60.83,-76.56$. HRMS (EI) calcd for $\mathrm{C}_{21} \mathrm{H}_{14} \mathrm{~F}_{6} \mathrm{~N}_{4} \mathrm{O}_{2} \mathrm{~S}[\mathrm{M}+\mathrm{H}]^{+}: 501.0814$, found: 501.0815 .

5-(4,4-Dimethyl-5-oxo-2-thioxo-3-(4-(2,2,2-trifluoro-1-hydro-xyeth-yl)phenyl)imidazolidin-1-yl)-3-(trifluoromethyl)picolinonitrile (13f). ${ }^{1} \mathrm{H} \mathrm{NMR}\left(400 \mathrm{MHz}, \mathrm{CDCl}_{3}\right) \delta 9.08(\mathrm{dd}, J=12.6,2.2 \mathrm{~Hz}, 1 \mathrm{H}), 8.37$ $(\mathrm{t}, J=3.9 \mathrm{~Hz}, 1 \mathrm{H}), 7.67(\mathrm{dd}, J=18.2,8.3 \mathrm{~Hz}, 2 \mathrm{H}), 7.45-7.31(\mathrm{~m}$, $2 \mathrm{H}), 5.13(\mathrm{q}, J=6.6 \mathrm{~Hz}, 1 \mathrm{H}), 1.63(\mathrm{~s}, 6 \mathrm{H}) .{ }^{13} \mathrm{C}$ NMR $(101 \mathrm{MHz}$, $\left.\mathrm{CDCl}_{3}\right) \delta 179.08,174.67,152.34,135.96,135.72,134.16$ (q, $J=$ $4.2 \mathrm{~Hz}), 132.41,130.54(\mathrm{q}, J=34.3 \mathrm{~Hz}), 129.96,129.67,129.15$, $124.04(\mathrm{q}, J=283.1 \mathrm{~Hz}), 121.26(\mathrm{q}, J=270.9 \mathrm{~Hz}), 113.75,71.99$ (q, $J=26.3 \mathrm{~Hz}), 66.81,23.76 .{ }^{19} \mathrm{~F}$ NMR $\left(376 \mathrm{MHz}, \mathrm{CDCl}_{3}\right.$ ) $\delta-61.87,-78.12$. HRMS (EI) calcd for $\mathrm{C}_{20} \mathrm{H}_{14} \mathrm{~F}_{6} \mathrm{~N}_{4} \mathrm{O}_{2} \mathrm{~S}^{+}[\mathrm{M}+\mathrm{H}]^{+}$: 489.0814, found: 489.0815 .

General procedure for the synthesis of $13 \mathrm{~g}-\mathbf{j}$. To the mixture of compound 12a (54 mg, $0.17 \mathrm{mmol}$ ) and compound 10b ( $79 \mathrm{mg}, 0.34 \mathrm{mmol})$ in DMAc $(10 \mathrm{~mL})$, the mixture was heated to $80{ }^{\circ} \mathrm{C}$ for $24 \mathrm{~h}$, and then $\mathrm{MeOH}(2 \mathrm{~mL})$ and $1 \mathrm{~N} \mathrm{HCl}(1 \mathrm{~mL})$ added in the mixture. The reaction mixture was stirred at $90{ }^{\circ} \mathrm{C}$ for $2 \mathrm{~h}$. After completion of the reaction (TLC), water $(30 \mathrm{~mL})$ were added. The resulting mixture was extracted with ethyl acetate, washed with brine, dried over sodium sulfate, concentrated and purified by column chromatography (PE:EA/1:1) to give a brown solid as crude product, which was purified by preparative chromatography to give compound $\mathbf{1 3 g}$ as a white solid (26 mg, 28\% yield).

Compounds $\mathbf{1 3 h}-\mathbf{j}$ were synthesized by a similar procedure as described for compound $\mathbf{1 3 g}$.

4-(1-(3-Fluoro-4-(2,2,2-trifluoro-1-hydroxyethyl)phenyl)-4-oxo-2thioxo-1,3-diazaspiro[4.5]decan-3-yl)-2-(trifluoromethyl)benzo-nitrile (13g). ${ }^{1} \mathrm{H}$ NMR (400 MHz, $\left.\mathrm{CDCl}_{3}\right) \delta 7.99(\mathrm{t}, J=10.4 \mathrm{~Hz}, 1 \mathrm{H}), 7.94$ (d, $J=1.7 \mathrm{~Hz}, 1 \mathrm{H}), 7.89-7.78(\mathrm{~m}, 2 \mathrm{H}), 7.17-7.10(\mathrm{~m}, 1 \mathrm{H}), 7.05$ (dd, $J=9.9,1.9 \mathrm{~Hz}, 1 \mathrm{H}), 5.61-5.38(\mathrm{~m}, 1 \mathrm{H}), 3.03-2.80(\mathrm{~m}, 1 \mathrm{H})$, 2.26-1.98 (m, 4H), 1.87-1.64 (m, 5H), 1.17-1.00 (m, 1H). ${ }^{13} \mathrm{C}$ NMR $\left(101 \mathrm{MHz}, \mathrm{CDCl}_{3}\right) \delta 180.12,173.49,160.36(\mathrm{~d}, J=251.3$ $\mathrm{Hz}), 137.10$ (d, $J=10.0 \mathrm{~Hz}), 136.95,135.25,133.32(\mathrm{q}, J=33.8$. $\mathrm{Hz}), 132.31,130.06$ (d, $J=4.6 \mathrm{~Hz}), 127.22(\mathrm{q}, J=3.2 \mathrm{~Hz}), 127.98$ $(\mathrm{d}, J=3.1 \mathrm{~Hz}), 123.86(\mathrm{q}, J=280.1 \mathrm{~Hz}), 123.52(\mathrm{~d}, J=14.0 \mathrm{~Hz})$, $122.36(\mathrm{q}, J=283.3 \mathrm{~Hz}), 118.26(\mathrm{~d}, J=23.3 \mathrm{~Hz}), 114.80,110.19$, $67.73,65.97$ (q, $J=61.4 \mathrm{~Hz}), 32.82,23.86,20.90 .{ }^{19} \mathrm{~F}$ NMR $(376$ $\mathrm{MHz}_{\mathrm{CDCl}}$ ) $\delta-62.04,-78.37,-113.90$. HRMS (EI) calcd for $\mathrm{C}_{24} \mathrm{H}_{18} \mathrm{~F}_{7} \mathrm{~N}_{3} \mathrm{O}_{2} \mathrm{~S}[\mathrm{M}+\mathrm{H}]^{+}$: 546.1081, found: 546.1086.

4-(4-Oxo-2-thioxo-1-(4-(2,2,2-trifluoro-1-hydroxyethyl)phenyl)1,3-diazaspiro[4.4]nonan-3-yl)-2-(trifluoromethyl)benzonitrile (13h). ${ }^{1} \mathrm{H}$ NMR (400 MHz, $\mathrm{CDCl}_{3}$ ) $\delta 7.98(\mathrm{dd}, J=4.7,3.2 \mathrm{~Hz}, 2 \mathrm{H}), 7.90-$ $7.83(\mathrm{~m}, 1 \mathrm{H}), 7.69$ (d, $J=8.2 \mathrm{~Hz}, 2 \mathrm{H}), 7.39$ (d, $J=8.3 \mathrm{~Hz}, 2 \mathrm{H})$, 5.25-5.05 (m, 1H), 3.07-2.49 (m, 1H), 2.34 (dt, $J=13.2,6.2 \mathrm{~Hz}$, $2 \mathrm{H}), 2.23-2.11(\mathrm{~m}, 2 \mathrm{H}), 1.94-1.82(\mathrm{~m}, 2 \mathrm{H}), 1.66-1.44(\mathrm{~m}, 3 \mathrm{H})$. ${ }^{13} \mathrm{C}$ NMR (101 MHz, CDCl3) $\delta$ 180.19, 176.05, 137.19, 136.74, 135.58, 135.20, 133.61 (q, $J=37.0 \mathrm{~Hz}$ ), 132.19, 130.21, 129.09, $127.12(\mathrm{q}, J=4.8 \mathrm{~Hz}), 123.73$ (q, $J=279.6 \mathrm{~Hz}), 121.84$ (q, $J=$ $270.7 \mathrm{~Hz}$ ), 114.83, 110.17, 75.27, 72.10 (q, $J=32.3 \mathrm{~Hz}), 36.16$, 25.12. $\left.{ }^{19} \mathrm{~F} \mathrm{NMR} \mathrm{(376} \mathrm{MHz,} \mathrm{CDCl}_{3}\right) \delta-61.96,-78.19$. HRMS (EI) calcd for $\mathrm{C}_{23} \mathrm{H}_{17} \mathrm{~F}_{6} \mathrm{~N}_{3} \mathrm{O}_{2} \mathrm{~S}[\mathrm{M}+\mathrm{H}]^{+}$: 514.1018, found: 514.1023.

4-(4-Oxo-2-thioxo-1-(4-(2,2,2-trifluoro-1-hydroxyethyl)phenyl)1,3-diazaspiro[4.5]decan-3-yl)-2-(trifluoromethyl)benzonitr-ile (13i). ${ }^{1} \mathrm{H}$ NMR $\left(400 \mathrm{MHz}, \mathrm{CDCl}_{3}\right) \delta 8.05-7.90(\mathrm{~m}, 2 \mathrm{H}), 7.83(\mathrm{dd}, J=8.2$,
$1.7 \mathrm{~Hz}, 1 \mathrm{H}), 7.67(\mathrm{~d}, J=8.2 \mathrm{~Hz}, 2 \mathrm{H}), 7.31(\mathrm{t}, J=9.3 \mathrm{~Hz}, 2 \mathrm{H}), 5.12$ (q, $J=6.6 \mathrm{~Hz}, 1 \mathrm{H}), 3.28-2.83(\mathrm{~m}, 1 \mathrm{H}), 2.19-2.00(\mathrm{~m}, 4 \mathrm{H}), 1.70$ $(\mathrm{dd}, J=17.4,7.1 \mathrm{~Hz}, 5 \mathrm{H}), 1.17-1.00(\mathrm{~m}, 1 \mathrm{H}) .{ }^{13} \mathrm{C} \mathrm{NMR}(101 \mathrm{MHz}$, $\left.\mathrm{CDCl}_{3}\right) \delta 180.07,173.81,137.12,135.76,135.21,133.57$ (q, $J=$ $34.0 \mathrm{~Hz}), 132.36,130.69,128.99,127.32$ (q, $J=5.0 \mathrm{~Hz}), 124.05$ (q, $J=278.0 \mathrm{~Hz}), 121.90(\mathrm{q}, J=273.0 \mathrm{~Hz}), 114.86,110.08,72.05(\mathrm{q}, J$ $=32.0 \mathrm{~Hz}), 67.62,32.75,23.88,20.69 .{ }^{19} \mathrm{~F} \mathrm{NMR}(376 \mathrm{MHz}$, $\left.\mathrm{CDCl}_{3}\right) \delta-61.94,-78.07$. HRMS (EI) calcd for $\mathrm{C}_{24} \mathrm{H}_{19} \mathrm{~F}_{6} \mathrm{~N}_{3} \mathrm{O}_{2} \mathrm{~S}$ $[\mathrm{M}+\mathrm{H}]^{+}: 528.1175$, found: 528.1183 .

4-(7,7-Dimethyl-4-oxo-2-thioxo-1-(4-(2,2,2-trifluoro-1-hydroxyeth-yl)phenyl)-1,3-diazaspiro[4.5]decan-3-yl)-2-(trifluoromethyl) benz-onitrile (13j). ${ }^{1} \mathrm{H}$ NMR $\left(400 \mathrm{MHz}, \mathrm{CDCl}_{3}\right) \delta 8.04-7.89(\mathrm{~m}$, $2 \mathrm{H}), 7.90-7.77(\mathrm{~m}, 1 \mathrm{H}), 7.75-7.64(\mathrm{~m}, 2 \mathrm{H}), 7.28(\mathrm{t}, J=6.1 \mathrm{~Hz}$, $2 \mathrm{H}), 5.27-5.01(\mathrm{~m}, 1 \mathrm{H}), 3.17-2.69(\mathrm{~m}, 1 \mathrm{H}), 2.36-2.20(\mathrm{~m}, 1 \mathrm{H})$, 2.21-2.10 (m, 1H), 1.98-1.86 (m, 1H), 1.73-1.60 (m, 3H), 1.57$1.46(\mathrm{~m}, 2 \mathrm{H}), 1.22$ (d, $J=14.6 \mathrm{~Hz}, 3 \mathrm{H}), 0.98-0.90(\mathrm{~m}, 3 \mathrm{H}) .{ }^{13} \mathrm{C}$ NMR (101 MHz, $\left.\mathrm{CDCl}_{3}\right) \delta 180.04,174.36,137.23,135.66,135.17$, 133.57 (q, $J=34.0 \mathrm{~Hz}), 132.40,131.28,128.98,127.32(\mathrm{q}, J=5.0$ $\mathrm{Hz}), 124.05$ (q, $J=281.2 \mathrm{~Hz}), 121.89$ (q, $J=272.5 \mathrm{~Hz}), 114.84$, 110.11, 72.09 (q, $J=32.5 \mathrm{~Hz}), 68.81,43.20,37.41,35.03,32.48$, 32.19, 26.36, 17.95. ${ }^{19} \mathrm{~F}$ NMR (376 $\left.\mathrm{MHz}, \mathrm{CDCl}_{3}\right) \delta-61.96$, -78.04. HRMS (EI) calcd for $\mathrm{C}_{26} \mathrm{H}_{23} \mathrm{~F}_{6} \mathrm{~N}_{3} \mathrm{O}_{2} \mathrm{~S}[\mathrm{M}+\mathrm{H}]^{+}$: 556.1488, found: 556.1494 .

General procedure for the synthesis of $14 a-d$ and $15 a-e$. At $0{ }^{\circ} \mathrm{C}$, DCM solution of 13a (505 mg, $1 \mathrm{mmol}$ ), $\mathrm{Et}_{3} \mathrm{~N}$ (151 mg, 1.5 $\mathrm{mmol}$ ) and $\mathrm{MsCl}$ (137 mg, $1.2 \mathrm{mmol}$ ) were added in this order. The reaction was stirred at room temperature for $30 \mathrm{~min}$, and concentrated under vacuum to give the crude product for the flowing reaction. A stirred solution of the crude product and aqueous ammonia in THF was refluxed overnight, and concentrated under vacuum to give the crude product. Purification by flash chromatography afforded the products 14a (410 mg, 79\% yield).

Compounds 14b-d and 15b-e were synthesized by a similar procedure as described for compound $\mathbf{1 4 a}$.

4-(3-(3-Fluoro-4-(2,2,2-trifluoro-1-(methylamino)ethyl)phenyl)4,4-dimethyl-5-oxo-2-thioxoimidazolidin-1-yl)-2-(trifluoromethyl) ben-zonitrile (14a). ${ }^{1} \mathrm{H}$ NMR $\left(400 \mathrm{MHz}, \mathrm{CDCl}_{3}\right) \delta 8.04-7.91(\mathrm{~m}$, $2 \mathrm{H}), 7.89-7.78(\mathrm{~m}, 1 \mathrm{H}), 7.68(\mathrm{t}, J=7.9 \mathrm{~Hz}, 1 \mathrm{H}), 7.22-7.16(\mathrm{~m}$, 1H), 7.16-7.05 (m, 1H), 4.75-4.38 (m, 1H), $2.49(\mathrm{~s}, 3 \mathrm{H}), 1.70$ (ddd, $J=11.6,10.6,7.5 \mathrm{~Hz}, 1 \mathrm{H}), 1.62(\mathrm{~s}, 6 \mathrm{H}) .{ }^{13} \mathrm{C}$ NMR (101 $\left.\mathrm{MHz}, \mathrm{CDCl}_{3}\right) \delta 179.78,174.59,162.34(\mathrm{~d}, J=251.6 \mathrm{~Hz}), 136.89$, $136.80(\mathrm{~d}, J=9.8 \mathrm{~Hz}), 135.29,133.66(\mathrm{q}, J=33.2 \mathrm{~Hz}), 132.13$, $130.13(\mathrm{~d}, J=4.0 \mathrm{~Hz}), 127.08(\mathrm{q}, J=4.1 \mathrm{~Hz}), 126.02(\mathrm{~d}, J=3.8$ $\mathrm{Hz}), 125.07$ (q, $J=277.2 \mathrm{~Hz}), 123.59$ (q, $J=14.0 \mathrm{~Hz}) 121.84$ (q, $J$ $=273.1 \mathrm{~Hz}), 117.49$ (q, $J=23.9 \mathrm{~Hz}), 114.76,110.36,66.59,58.65$ $(\mathrm{q}, J=27.5 \mathrm{~Hz}), 34.84,23.81 .{ }^{19} \mathrm{~F} \mathrm{NMR}\left(376 \mathrm{MHz}, \mathrm{CDCl}_{3}\right.$ ) $\delta-61.88,-78.43,-78.45,-113.50,-113.52$. HRMS (EI) calcd for $\mathrm{C}_{22} \mathrm{H}_{17} \mathrm{~F}_{7} \mathrm{~N}_{4} \mathrm{OS}[\mathrm{M}+\mathrm{H}]^{+}$: 519.1084, found: 519.1093 .

4-(3-(3-Fluoro-4-(2,2,2-trifluoro-1-((2-hydroxyethyl)amino)ethyl) phenyl)-4,4-dimethyl-5-oxo-2-thioxoimidazolidin-1-yl)-2-(trifluoromethyl)benzonitrile (14b). ${ }^{1} \mathrm{H} \mathrm{NMR}\left(400 \mathrm{MHz}, \mathrm{CDCl}_{3}\right) \delta 8.04-7.91$ $(\mathrm{m}, 2 \mathrm{H}), 7.85(\mathrm{t}, J=10.9 \mathrm{~Hz}, 1 \mathrm{H}), 7.68(\mathrm{t}, J=7.9 \mathrm{~Hz}, 1 \mathrm{H}), 7.18(\mathrm{t}, J$ $=9.0 \mathrm{~Hz}, 1 \mathrm{H}), 7.12(\mathrm{~d}, J=9.9 \mathrm{~Hz}, 1 \mathrm{H}), 4.67(\mathrm{q}, J=7.0 \mathrm{~Hz}, 1 \mathrm{H})$, 3.91-3.51 (m, 2H), 3.13-2.51 (m, 2H), 2.28-1.90 (m, 2H), $1.62(\mathrm{~s}$, $6 \mathrm{H}) .{ }^{13} \mathrm{C}$ NMR $\left(101 \mathrm{MHz}, \mathrm{CDCl}_{3}\right) \delta 179.81,174.58,161.20(\mathrm{~d}, J=$ $251.0 \mathrm{~Hz}), 136.92,136.91(\mathrm{~d}, J=9.9 \mathrm{~Hz}), 135.31,133.69$ (q, $J=$ 
$33.1 \mathrm{~Hz}), 132.18,130.05(\mathrm{~d}, J=4.0 \mathrm{~Hz}), 127.10(\mathrm{q}, J=4.8 \mathrm{~Hz})$, $126.08(\mathrm{~d}, J=3.0 \mathrm{~Hz}), 124.93(\mathrm{q}, J=281.1 \mathrm{~Hz}), 123.84(\mathrm{~d}, J=13.8$ $\mathrm{Hz}), 121.85$ (q, $J=273.1 \mathrm{~Hz}), 117.58$ (d, $J=24.3 \mathrm{~Hz}), 114.76$, 110.36, 66.62, 61.26, 56.93 (q, $J=24.3 \mathrm{~Hz}), 49.51,23.81 .{ }^{19} \mathrm{~F}$ NMR (376 MHz, $\left.\mathrm{CDCl}_{3}\right) \delta-61.94,-73.19,-113.75$. HRMS (EI) calcd for $\mathrm{C}_{23} \mathrm{H}_{19} \mathrm{~F}_{7} \mathrm{~N}_{4} \mathrm{O}_{2} \mathrm{~S}[\mathrm{M}+\mathrm{H}]^{+}: 549.1190$, found: 549.1191 .

4-(3-(3-Fluoro-4-(2,2,2-trifluoro-1-((1-hydroxy-2-methylpro-pan2-yl)amino)ethyl)phenyl)-4,4-dimethyl-5-oxo-2-thioxoi-midazolidin1-yl)-2-(trifluoromethyl)benzonitrile (14c). ${ }^{1} \mathrm{H}$ NMR $(400 \mathrm{MHz}$, $\left.\mathrm{CDCl}_{3}\right) \delta 7.91(\mathrm{~d}, J=8.6 \mathrm{~Hz}, 2 \mathrm{H}), 7.82-7.74(\mathrm{~m}, 1 \mathrm{H}), 7.59-7.45$ (m, 2H), 7.23 (dd, $J=18.1,4.6 \mathrm{~Hz}, 2 \mathrm{H}), 4.32-4.11(\mathrm{~m}, 1 \mathrm{H}), 3.41-$ $3.24(\mathrm{~m}, 1 \mathrm{H}), 3.22-3.07(\mathrm{~m}, 1 \mathrm{H}), 2.14-1.85$ (m, 1H), 1.69-1.61 (m, 1H), $1.53(\mathrm{~s}, 6 \mathrm{H}), 0.95$ (d, $J=11.9 \mathrm{~Hz}, 6 \mathrm{H}) .{ }^{13} \mathrm{C}$ NMR (101 $\left.\mathrm{MHz}, \mathrm{CDCl}_{3}\right) \delta 179.80,174.58,161.35(\mathrm{~d}, J=257.0 \mathrm{~Hz}), 136.92$, $136.69(\mathrm{~d}, J=10.0 \mathrm{~Hz}), 135.30,133.65(\mathrm{q}, J=33.0 \mathrm{~Hz}), 132.15$, $130.05(\mathrm{~d}, J=4.0 \mathrm{~Hz}), 127.09$ (q, $J=5.0 \mathrm{~Hz}), 126.79$ (d, $J=14.1$ $\mathrm{Hz}), 126.13$ (d, $J=4.0 \mathrm{~Hz}), 124.81$ (q, $J=280.3 \mathrm{~Hz}), 121.85$ (q, $J=$ 273.1 Hz), 117.53 (d, $J=24.0 \mathrm{~Hz}$ ), 114.76, 110.33, 69.35, 66.54, 54.91, 51.21 (q, $J=29.3 \mathrm{~Hz}), 24.81,23.93,23.82 .{ }^{19} \mathrm{~F}$ NMR (376 $\left.\mathrm{MHz}, \mathrm{CDCl}_{3}\right) \delta-61.95,-74.66,-114.24$. HRMS (EI) calcd for $\mathrm{C}_{25} \mathrm{H}_{23} \mathrm{~F}_{7} \mathrm{~N}_{4} \mathrm{O}_{2} \mathrm{~S}[\mathrm{M}+\mathrm{H}]^{+}$: 577.1503, found: 577.1504.

4-(3-(4-(1-((2,3-Dihydroxypropyl)amino)-2,2,2-trifluoroethyl)-3fluorophenyl)-4,4-dimethyl-5-oxo-2-thioxoimidazolidin-1-yl)-2(trifluoromethyl)benzonitrile (14d). ${ }^{1} \mathrm{H}$ NMR (400 $\mathrm{MHz}, \mathrm{CDCl}_{3}$ )

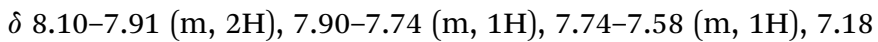
$(\mathrm{t}, J=9.6 \mathrm{~Hz}, 1 \mathrm{H}), 7.13(\mathrm{~d}, J=10.0 \mathrm{~Hz}, 1 \mathrm{H}), 4.73-4.51(\mathrm{~m}, 1 \mathrm{H})$, 3.92-3.69 (m, 2H), 3.67-3.52 (m, 1H), 2.92-2.83 (m, 1H), 2.82$2.70(\mathrm{~m}, 1 \mathrm{H}), 2.49-2.05(\mathrm{~m}, 2 \mathrm{H}), 1.62(\mathrm{~s}, 6 \mathrm{H}) .{ }^{13} \mathrm{C}$ NMR $(101 \mathrm{MHz}$, $\left.\mathrm{CDCl}_{3}\right) \delta 179.82,174.55,161.20(\mathrm{~d}, J=261.1 \mathrm{~Hz}), 137.03(\mathrm{~d}, J=$ 8.5 Hz), 136.99, 136.89, 135.31, 133.69 (q, $J=33.4 \mathrm{~Hz}$ ), 132.17, $129.94(\mathrm{~d}, J=5.1 \mathrm{~Hz}), 127.11(\mathrm{q}, J=5.1 \mathrm{~Hz}), 126.14(\mathrm{~d}, J=4.1$ $\mathrm{Hz}), 124.84$ (q, $J=277.3 \mathrm{~Hz}), 119.15(\mathrm{q}, J=270.6 \mathrm{~Hz}), 117.68(\mathrm{~d}, J$ $=24.1 \mathrm{~Hz}), 114.74,110.41,70.15(\mathrm{~d}, J=30.2 \mathrm{~Hz}), 66.62,65.02(\mathrm{~d}$, $J=12.3 \mathrm{~Hz}), 57.20(\mathrm{q}, J=30.3 \mathrm{~Hz}), 50.21,23.83 .{ }^{19} \mathrm{~F}$ NMR $(377$ $\left.\mathrm{MHz}, \mathrm{CDCl}_{3}\right) \delta-61.99,-73.69,-73.71,-73.72,-113.60$, -113.61, -113.66, -113.67. HRMS (EI) calcd for $\mathrm{C}_{24} \mathrm{H}_{21} \mathrm{~F}_{7} \mathrm{~N}_{4} \mathrm{O}_{3} \mathrm{~S}$ $[\mathrm{M}+\mathrm{H}]^{+}:$579.1295, found: 579.1299.

4-(3-(4-(1-Amino-2,2,2-trifluoroethyl)phenyl)-4,4-dimethyl-5-oxo2-thioxoimidazolidin-1-yl)-2-(trifluoromethyl)benzonitrile (15a). ${ }^{1} \mathrm{H}$ NMR (400 MHz, $\mathrm{CDCl}_{3}$ ) $\delta 8.12-7.93(\mathrm{~m}, 2 \mathrm{H}), 7.91-7.76(\mathrm{~m}$, $1 \mathrm{H}), 7.74-7.55(\mathrm{~m}, 2 \mathrm{H}), 7.35(\mathrm{~d}, J=8.4 \mathrm{~Hz}, 2 \mathrm{H}), 4.66-4.40(\mathrm{~m}$, 1H), 1.93-1.77 (m, 2H), 1.60 (s, 6H). $\left.{ }^{13} \mathrm{C} \mathrm{NMR} \mathrm{(101} \mathrm{MHz,} \mathrm{CDCl}_{3}\right)$ $\delta 179.86,174.90,137.15,137.09,135.66,135.27,133.59$ (q, $J=$ $33.1 \mathrm{~Hz}$ ), 132.24, 129.84, 129.53, 127.14 (q, $J=4.3 \mathrm{~Hz}), 125.37$ (q, $J=280.6 \mathrm{~Hz}), 121.89$ (q, $J=272.7 \mathrm{~Hz}), 114.83,110.22,66.53$, 57.51 (q, $J=31.2 \mathrm{~Hz}$ ), 23.75. ${ }^{19} \mathrm{~F}$ NMR (376 MHz, $\mathrm{CDCl}_{3}$ ) $\delta-61.95,-76.41$. HRMS (EI) calcd for $\mathrm{C}_{21} \mathrm{H}_{16} \mathrm{~F}_{6} \mathrm{~N}_{4} \mathrm{OS}[\mathrm{M}+\mathrm{H}]^{+}$: 487.1022, found: 487.1025 .

4-(4,4-Dimethyl-5-oxo-2-thioxo-3-(4-(2,2,2-trifluoro-1-(methylamino)ethyl)phenyl)imidazolidin-1-yl)-2-(trifluoromethyl)ben-zonitrile (15b). ${ }^{1} \mathrm{H}$ NMR $\left(400 \mathrm{MHz}, \mathrm{CDCl}_{3}\right.$ ) $\delta$ 8.05-7.95 (m, 2H), 7.89-7.82 $(\mathrm{m}, 1 \mathrm{H}), 7.61(\mathrm{~d}, J=8.3 \mathrm{~Hz}, 2 \mathrm{H}), 7.40-7.32(\mathrm{~m}, 2 \mathrm{H}), 4.23-4.07$ $(\mathrm{m}, 1 \mathrm{H}), 2.47(\mathrm{~s}, 3 \mathrm{H}), 1.61(\mathrm{~d}, J=2.0 \mathrm{~Hz}, 6 \mathrm{H}) .{ }^{13} \mathrm{C}$ NMR (101 $\left.\mathrm{MHz}, \mathrm{CDCl}_{3}\right) \delta 179.82,174.92,137.11,135.99,135.71,135.26$, 133.57 (q, $J=33.8 \mathrm{~Hz}), 132.24,130.06,129.85,127.12(\mathrm{q}, J=5.1$ $\mathrm{Hz}), 125.14$ (q, $J=280.2 \mathrm{~Hz}), 121.89$ (q, $J=272.5 \mathrm{~Hz}), 114.83$, 110.21, 66.53, 66.02 (q, $J=32.1 \mathrm{~Hz}), 34.85,23.76 .{ }^{19} \mathrm{~F}$ NMR
(377 $\left.\mathrm{MHz}, \mathrm{CDCl}_{3}\right) \delta-61.98,-73.81$. HRMS (EI) calcd for $\mathrm{C}_{22} \mathrm{H}_{18} \mathrm{~F}_{6} \mathrm{~N}_{4} \mathrm{OS}[\mathrm{M}+\mathrm{H}]^{+}:$501.1178, found: 501.1188 .

4-(4,4-Dimethyl-5-oxo-2-thioxo-3-(4-(2,2,2-trifluoro-1-((2-hydroxyethyl)amino)ethyl)phenyl)imidazolidin-1-yl)-2-(trifluoromethyl) benzonitrile (15c). ${ }^{1} \mathrm{H}$ NMR (400 $\left.\mathrm{MHz} \mathrm{CDCl}_{3}\right) \delta 7.99(\mathrm{~d}, J=$ $8.4 \mathrm{~Hz}, 2 \mathrm{H}), 7.92-7.77(\mathrm{~m}, 1 \mathrm{H}), 7.62(\mathrm{t}, J=13.0 \mathrm{~Hz}, 2 \mathrm{H}), 7.42-$ $7.27(\mathrm{~m}, 2 \mathrm{H}), 4.28(\mathrm{q}, J=7.2 \mathrm{~Hz}, 1 \mathrm{H}), 3.85-3.51(\mathrm{~m}, 2 \mathrm{H}), 2.97-$ $2.65(\mathrm{~m}, 2 \mathrm{H}), 2.01(\mathrm{~s}, 2 \mathrm{H}), 1.61(\mathrm{~s}, 6 \mathrm{H}) .{ }^{13} \mathrm{C}$ NMR $(101 \mathrm{MHz}$, $\left.\mathrm{CDCl}_{3}\right) \delta 179.83,174.89,137.07,136.11,135.77,135.26,133.60$ $(\mathrm{q}, J=33.2 \mathrm{~Hz}), 132.23,129.97,129.93,127.14(\mathrm{q}, J=4.8 \mathrm{~Hz})$, $125.13(\mathrm{q}, J=281.2 \mathrm{~Hz}), 121.88(\mathrm{q}, J=273.2 \mathrm{~Hz}), 114.82,110.23$, $66.54,64.06$ (q, $J=28.6 \mathrm{~Hz}), 61.37,49.41,23.77 .{ }^{19} \mathrm{~F} \mathrm{NMR}(376$ $\left.\mathrm{MHz}, \mathrm{CDCl}_{3}\right) \delta-61.96,-73.78$. HRMS (EI) calcd for $\mathrm{C}_{23} \mathrm{H}_{20} \mathrm{~F}_{6} \mathrm{~N}_{4} \mathrm{O}_{2} \mathrm{~S}[\mathrm{M}+\mathrm{H}]^{+}$: 531.1284, found: 531.1288 .

4-(4,4-Dimethyl-5-oxo-2-thioxo-3-(4-(2,2,2-trifluoro-1-((1-hydroxy2-methylpropan-2-yl)amino)ethyl)phenyl)imida-zolidin-1-yl)-2(trifluoromethyl)benzonitrile (15d). ${ }^{1} \mathrm{H} \mathrm{NMR}\left(400 \mathrm{MHz}, \mathrm{CDCl}_{3}\right.$ ) $\delta 7.91(\mathrm{~d}, J=8.6 \mathrm{~Hz}, 2 \mathrm{H}), 7.82-7.74(\mathrm{~m}, 1 \mathrm{H}), 7.51(\mathrm{~d}, J=8.1 \mathrm{~Hz}$, $2 \mathrm{H}), 7.26(\mathrm{~d}, J=8.2 \mathrm{~Hz}, 2 \mathrm{H}), 4.40-4.15(\mathrm{~m}, 1 \mathrm{H}), 3.39-3.23(\mathrm{~m}$, 1H), 3.24-3.09 (m, 1H), 2.15-1.87 (m, 1H), 1.79-1.64 (m, 2H), $1.53(\mathrm{~s}, 6 \mathrm{H}), 0.95$ (d, $J=11.9 \mathrm{~Hz}, 6 \mathrm{H}) .{ }^{13} \mathrm{C} \mathrm{NMR}(101 \mathrm{MHz}$, $\left.\mathrm{CDCl}_{3}\right) \delta 179.80,174.88,139.13,137.06,135.48,135.25,133.60$ $(\mathrm{q}, J=33.1 \mathrm{~Hz}), 132.18,129.96,129.51,127.13(\mathrm{q}, J=4.9 \mathrm{~Hz})$, $125.26(\mathrm{q}, J=279.3 \mathrm{~Hz}), 121.88(\mathrm{q}, J=273.4 \mathrm{~Hz}), 114.81,110.24$, $69.46,66.47,58.32(\mathrm{q}, J=29.6 \mathrm{~Hz}), 55.04,25.05,24.27,23.80 .{ }^{19} \mathrm{~F}$ NMR (376 MHz, $\left.\mathrm{CDCl}_{3}\right) \delta-61.97,-74.32$. HRMS (EI) calcd for $\mathrm{C}_{25} \mathrm{H}_{24} \mathrm{~F}_{6} \mathrm{~N}_{4} \mathrm{O}_{2} \mathrm{~S}[\mathrm{M}+\mathrm{H}]^{+}$: 559.1597, found: 559.1600.

4-(3-(4-(1-((2,3-Dihydroxypropyl)amino)-2,2,2-trifluoroethyl) phen-yl)-4,4-dimethyl-5-oxo-2-thioxoimidazolidin-1-yl)-2-(trifluorometh-yl)benzonitrile (15e). ${ }^{1} \mathrm{H}$ NMR $\left(400 \mathrm{MHz}, \mathrm{CDCl}_{3}\right) \delta 8.06-7.94$ (m, 2H), 7.88-7.80 (m, 1H), 7.66-7.55 (m, 2H), 7.41-7.32 (m, 2H), 4.25 (qd, $J=7.1,2.3 \mathrm{~Hz}, 1 \mathrm{H}), 3.87-3.76(\mathrm{~m}, 1 \mathrm{H}), 3.73(\mathrm{dt}, J=11.3$, $3.3 \mathrm{~Hz}, 1 \mathrm{H}), 3.60$ (ddd, $J=11.5,6.3,5.4 \mathrm{~Hz}, 1 \mathrm{H}), 2.84(\mathrm{dt}, J=12.0$, $3.6 \mathrm{~Hz}, 1 \mathrm{H}), 2.77-2.67(\mathrm{~m}, 1 \mathrm{H}), 2.20(\mathrm{~s}, 1 \mathrm{H}), 1.75-1.64(\mathrm{~m}, 2 \mathrm{H}), 1.61$ $(\mathrm{s}, 6 \mathrm{H}) .{ }^{13} \mathrm{C} \mathrm{NMR}\left(101 \mathrm{MHz}, \mathrm{CDCl}_{3}\right) \delta 179.84,174.93,137.03$, 135.90, 135.77, 135.26, 133.63 (q, $J=33.3 \mathrm{~Hz}$ ), 132.19, 130.02, $129.88,127.13(\mathrm{q}, J=4.8 \mathrm{~Hz}), 124.83(\mathrm{q}, J=281.3 \mathrm{~Hz}), 118.27$ (q, $J$ $=278.3 \mathrm{~Hz}), 114.79,110.29,70.21(\mathrm{~d}, J=36.2 \mathrm{~Hz}), 66.54,65.12(\mathrm{~d}$, $J=8.1 \mathrm{~Hz}), 64.33(\mathrm{q}, J=28.2 \mathrm{~Hz}), 50.37(\mathrm{~d}, J=45.3 \mathrm{~Hz}), 23.79 .{ }^{19} \mathrm{~F}$ NMR (376 MHz, $\left.\mathrm{CDCl}_{3}\right) \delta-61.97,-73.75,-73.78$. HRMS (EI) calcd for $\mathrm{C}_{24} \mathrm{H}_{22} \mathrm{~F}_{6} \mathrm{~N}_{4} \mathrm{O}_{3} \mathrm{~S}[\mathrm{M}+\mathrm{H}]^{+}: 561.1390$, found: 561.1390 .

4-(4,4-Dimethyl-5-oxo-2-thioxo-3-(4-(2,2,2-trifluoro-1-hydroxyethyl)phenyl)imidazolidin-1-yl)-2-(trifluoromethyl)benzoic acid (15f). In a $20 \mathrm{~mL}$ tube sealing, 13b $(49 \mathrm{mg}, 0.1 \mathrm{mmol})$, concentrated $\mathrm{H}_{2} \mathrm{SO}_{4}(5 \mathrm{~mL})$, were added. The mixture was sealed and stirred for $24 \mathrm{~h}$ at $100{ }^{\circ} \mathrm{C}$. After the reaction, the mixture was poured into $100 \mathrm{~mL}$ ice water and saturated sodium bicarbonate was added to adjust $\mathrm{pH}$ to 4 . The mixture was washed with EA (30 $\mathrm{mL} \times 3)$ and the organic layer was separated and dried over $\mathrm{Na}_{2} \mathrm{SO}_{4}$. After filtration and evaporation, the resulting crude product was purified by column chromatography with petrol ether as eluent to afford 15f (43 $\mathrm{mg}, 84 \%$ yield).

${ }^{1} \mathrm{H}$ NMR (400 MHz, DMSO) $\delta 8.06$ (d, $J=1.7 \mathrm{~Hz}, 1 \mathrm{H}$ ), 8.02$7.92(\mathrm{~m}, 1 \mathrm{H}), 7.88(\mathrm{dd}, J=8.2,1.7 \mathrm{~Hz}, 1 \mathrm{H}), 7.68(\mathrm{t}, J=9.4 \mathrm{~Hz}$, $2 \mathrm{H}), 7.48(\mathrm{t}, J=10.3 \mathrm{~Hz}, 2 \mathrm{H}), 5.52-5.13(\mathrm{~m}, 1 \mathrm{H}), 1.52(\mathrm{~s}, 6 \mathrm{H}) \cdot{ }^{13} \mathrm{C}$ NMR (101 MHz, CDCl3) $\delta 185.74,180.49,172.60,142.00,141.17$, 140.70, 138.48, 135.54, 134.91, 133.94, $132.82(\mathrm{q}, J=2.9 \mathrm{~Hz})$, 
$132.08(\mathrm{q}, J=32.1 \mathrm{~Hz}), 130.17(\mathrm{q}, J=282.7 \mathrm{~Hz}), 128.37,(\mathrm{q}, J=$ $273.0 \mathrm{~Hz}$ ), 75.18 (q, $J=29.8 \mathrm{~Hz}), 71.42,28.23 .{ }^{19} \mathrm{~F}$ NMR (376 $\left.\mathrm{MHz}, \mathrm{CDCl}_{3}\right) \quad \delta-53.41,-71.81$. HRMS (EI) calcd for $\mathrm{C}_{21} \mathrm{H}_{16} \mathrm{~F}_{6} \mathrm{~N}_{2} \mathrm{O}_{4} \mathrm{~S}[\mathrm{M}+\mathrm{H}]^{+}$: 507.0808, found: 507.0817 .

4-(4,4-Dimethyl-5-oxo-2-thioxo-3-(4-(2,2,2-trifluoro-1-hydroxyethyl)phenyl)imidazolidin-1-yl)-2-(trifluoromethyl)benza-mide (15g). To a mixture of $\mathbf{1 3 b}$ (49 $\mathrm{mg}, 0.1 \mathrm{mmol}$ ) and sodium hydroxide (4.0 $\mathrm{M}$ in water, $0.25 \mathrm{~mL}, 1.0 \mathrm{mmol}$ ) in DMSO $(2.5 \mathrm{~mL}$ ) was added hydrogen peroxide (30\% aqueous solution, $0.05 \mathrm{~mL}, 0.49$ $\mathrm{mmol})$. The reaction mixture was heated to $35{ }^{\circ} \mathrm{C}$. After 40 minutes, $20 \mathrm{~mL} \mathrm{H}_{2} \mathrm{O}$ was added, the mixtures was extracted with ethyl acetate. The organic layer was separated and dried over $\mathrm{Na}_{2} \mathrm{SO}_{4}$. After filtration and evaporation, the resulting crude product was purified by column chromatography with petrol ether as eluent to afford $\mathbf{1 5 g}$ ( $39 \mathrm{mg}, 77 \%$ yield).

${ }^{1} \mathrm{H}$ NMR (400 MHz, DMSO) $\delta$ 8.19-8.10 (m, 1H), 8.04-7.91 (m, 1H), 7.87-7.78 (m, 1H), 7.70 (dd, $J=16.7,7.3 \mathrm{~Hz}, 4 \mathrm{H}), 7.46$ (d, $J$ $=8.2 \mathrm{~Hz}, 2 \mathrm{H}), 7.09-6.91(\mathrm{~m}, 1 \mathrm{H}), 5.37-5.24(\mathrm{~m}, 1 \mathrm{H}), 1.51(\mathrm{~s}, 6 \mathrm{H})$. ${ }^{13} \mathrm{C}$ NMR (101 MHz, DMSO) $\delta 181.07,175.85,168.88,137.55$, $137.21,136.47,134.84,133.55,130.18,129.51,129.17,127.84$ (q, $J=5.1 \mathrm{~Hz}), 126.53,125.43(\mathrm{q}, J=283.1 \mathrm{~Hz}), 123.81(\mathrm{q}, J=273.3$ $\mathrm{Hz}), 70.47$ (q, $J=21.1 \mathrm{~Hz}), 66.62,23.51 .{ }^{19} \mathrm{~F}$ NMR $(376 \mathrm{MHz}$, DMSO) $\delta-57.99,-76.56$. HRMS (EI) calcd for $\mathrm{C}_{21} \mathrm{H}_{17} \mathrm{~F}_{6} \mathrm{~N}_{3} \mathrm{O}_{3} \mathrm{~S}$ $[\mathrm{M}+\mathrm{H}]^{+}:$506.0968, found: 506.0975.

4-(4,4-Dimethyl-5-oxo-2-thioxo-3-(4-(2,2,2-trifluoro-1-methoxyethyl)phenyl)imidazolidin-1-yl)-2-(trifluoromethyl)benzo-nitrile (15h). In a $25 \mathrm{~mL}$ round-bottomed flask, $13 \mathbf{b}$ (49 mg, $0.1 \mathrm{mmol})$, DMF (5 mL), and $\mathrm{NaH} 60 \%$ (12 mg, $0.3 \mathrm{mmol}$ ) were added. The mixture was stirred and simultaneously $\mathrm{CH}_{3} \mathrm{I}(12.3 \mathrm{mg} 0.3$ $\mathrm{mmol}$ ) was added then, the reaction was stirred for $2 \mathrm{~h}$ at room temperature. After the reaction, $20 \mathrm{~mL}$ saturated $\mathrm{NH}_{4} \mathrm{Cl}$ was added, the mixtures was extracted with ethyl acetate. The organic layer was separated and dried over $\mathrm{Na}_{2} \mathrm{SO}_{4}$. After filtration and evaporation, the resulting crude product was purified by column chromatography with petrol ether as eluent to afford $15 \mathrm{~h}$ ( $40 \mathrm{mg}, 77 \%$ yield).

${ }^{1} \mathrm{H}$ NMR (400 MHz, $\left.\mathrm{CDCl}_{3}\right) \delta 8.22-7.93(\mathrm{~m}, 2 \mathrm{H}), 7.86-7.84(\mathrm{~m}$, $1 \mathrm{H}), 7.63-7.57(\mathrm{~m}, 2 \mathrm{H}), 7.39-7.34(\mathrm{~m}, 2 \mathrm{H}), 4.61$ (dd, $J=11.0$, $4.6 \mathrm{~Hz}, 1 \mathrm{H}), 3.52-3.48(\mathrm{~m}, 3 \mathrm{H}), 1.61(\mathrm{~m}, 6 \mathrm{H}) .{ }^{13} \mathrm{C} \mathrm{NMR}(101 \mathrm{MHz}$, $\left.\mathrm{CDCl}_{3}\right) \delta 179.83,174.88,137.11,136.19,135.26,133.52(\mathrm{q}, J=$ $33.0 \mathrm{~Hz}$ ), 132.26, 129.82, 129.57, 127.15 (q, $J=4.8 \mathrm{~Hz}), 123.64$ (q, $J=281.0 \mathrm{~Hz}), 121.85(\mathrm{q}, J=276.3 \mathrm{~Hz}), 114.84,110.20,80.79$ (q, $J$ $=31.3 \mathrm{~Hz}), 66.56,58.99,23.75 .{ }^{19} \mathrm{~F}$ NMR (376 $\mathrm{MHz}, \mathrm{CDCl}_{3}$ ) $\delta-61.96,-62.02,-76.36,-76.47$. HRMS (EI) calcd for $\mathrm{C}_{22} \mathrm{H}_{17} \mathrm{~F}_{6} \mathrm{~N}_{3} \mathrm{O}_{2} \mathrm{~S}[\mathrm{M}+\mathrm{H}]^{+}$: 502.1018, found: 502.1020 .

4-(4,4-Dimethyl-5-oxo-2-thioxo-3-(4-(2,2,2-trifluoroacetyl)phenyl) imidazolidin-1-yl)-2-(trifluoromethyl)benzonitrile (15i). In a $25 \mathrm{~mL}$ round-bottomed flask, 13b (49 mg, $0.1 \mathrm{mmol}$ ), DMSO (5 mL), and IBX ( $84 \mathrm{mg}, 0.3 \mathrm{mmol}$ ) were added. The mixture was stirred for $12 \mathrm{~h}$ at room temperature. After the reaction, the mixture was poured over and filtered through a silica gel pad under vacuum the filtrate was added with $\mathrm{EA}(15 \mathrm{~mL})$ and washed with water $(20 \mathrm{~mL} \times 3)$ and saturated brine $(15 \mathrm{~mL} \times 3)$. The organic layer was separated and dried over $\mathrm{Na}_{2} \mathrm{SO}_{4}$. After filtration and evaporation, the resulting crude product was purified by column chromatography with petrol ether as eluent to afford 15i (45 mg, 90\% yield).
${ }^{1} \mathrm{H}$ NMR (400 MHz, $\left.\mathrm{CDCl}_{3}\right) \delta 8.24(\mathrm{dd}, J=22.9,8.3 \mathrm{~Hz}, 2 \mathrm{H})$, $7.99(\mathrm{dd}, J=9.2,4.7 \mathrm{~Hz}, 2 \mathrm{H}), 7.92-7.77$ (m, 1H), 7.58 (dd, $J=$ 22.9, 8.6 Hz, 2H), 1.79-1.52 (m, 6H). ${ }^{13} \mathrm{C} \mathrm{NMR} \mathrm{(101} \mathrm{MHz,} \mathrm{CDCl3)}$ $\delta 179.73,179.49(\mathrm{q}, J=35.1 \mathrm{~Hz}), 174.43,141.68,136.84,135.35$, $133.69(\mathrm{q}, J=34.9 \mathrm{~Hz}), 132.18,131.66,130.62,130.55,127.07$ (q, $J=5.1 \mathrm{~Hz}), 121.86(\mathrm{q}, J=273.4 \mathrm{~Hz}), 116.46(\mathrm{q}, J=290.1 \mathrm{~Hz})$, 114.76, 110.42, 66.76, 23.95. ${ }^{19} \mathrm{~F} \mathrm{NMR}\left(376 \mathrm{MHz}, \mathrm{CDCl}_{3}\right.$ ) $\delta-61.97,-71.55$. HRMS (EI) calcd for $\mathrm{C}_{21} \mathrm{H}_{13} \mathrm{~F}_{6} \mathrm{~N}_{3} \mathrm{O}_{2} \mathrm{~S}[\mathrm{M}+\mathrm{H}]^{+}$: 486.0705, found: 486.0708 .

\subsection{Cell proliferation inhibition assay}

Cell viability was determined using the CCK8 assay method. The cells were seeded in a 96-well plate at $3 \times 10^{3}$ cells per well for 24 hours $\left(37{ }^{\circ} \mathrm{C}, 5 \% \mathrm{CO}_{2}\right)$, and an equal volume of medium containing increasing concentration of inhibitors was added to each well. After a 5 days incubation, CCK8 reagent was added for 1.5 hours. The light absorption (OD) of the 96-well plate was measured at $490 \mathrm{~nm}$ using a SpectraMAX M5 microplate spectrophotometer (Molecular Devices). All experiments were performed in triplicate. The percentage of viable cells was calculated and compared with that of the control cells, the half maximal inhibitory concentration $\left(\mathrm{IC}_{50}\right)$ was calculated by GraphPad Prism5 software.

\subsection{Western blot analysis}

Cells were treated with a series of concentrations of $\mathbf{1 3 b}$ and ENT for 5 days at $37{ }^{\circ} \mathrm{C}$, then the cells were harvested, washed in ice-cold PBS, analyzed with RIPA buffer (10 mM Tris-HCl (pH 7.8), $1 \%$ NP40, $0.15 \mathrm{M} \mathrm{NaCl}, 1 \mathrm{mM}$ EDTA, $10 \mu \mathrm{M}$ aprotinin, $1 \mathrm{mM} \mathrm{NaF}$ and $1 \mathrm{mM} \mathrm{Na}_{3} \mathrm{VO}_{4}$ ), protease inhibitors, phosphatase cocktails A and B, and PMSF (1 mM). Protein concentration was determined by the BCA Protein Assay Kit (beyotime\#p0012s), the sample proteins were separated by $10 \%$ SDS-PAGE gel and transferred onto $0.2 \mathrm{um}$ polyvinylidene difluoride membranes (millpore\#ISEQ00010), then incubated overnight at $4{ }^{\circ} \mathrm{C}$ with the AR or PSA antibody overnight at the indicated concentrations in 5\% BSA/TBST buffer with gently shaking, then washing with $1 \times$ TBS/T 3 times and followed by incubation for 1.5 hour with a $1 / 5000$ dilution of secondary HRP antibody in 5\% nonfat milk/TBST. The target blots were detected with a chemiluminescence system.

\subsection{In vivo model}

The animal studies were carried out under protocols approved by the animal protection law of the People's Republic of China Care and Use Committees. All rodent studies were also carried out in accordance with the guidelines of Institutional Animal Care and Treatment Committee of Sichuan University in China. The male CB17 SCID mice were purchased (Beijing HFK Bioscience Co. ltd., Beijing, China). LNCap-AR cells were harvested during the exponential-growth phase, washed twice with serum-free medium, and re-suspended at a concentration of 1 $\times 10^{7} \mathrm{~mL}^{-1}$. One hundred microliters of the cell suspension was injected subcutaneously into the hind flank of each male CB17 SCID mouse (6-7 weeks old) after castrated 2 days. The tumors were allowed to grow to $100-150 \mathrm{~mm}^{3}$, at which point the mice 
were randomized into 5 groups ( 8 mice for each group). The mice were dosed orally with $13 \mathbf{b}$ (15 mg per kg q.d, $15 \mathrm{mg}$ per kg q.3d, or $5 \mathrm{mg}$ per $\mathrm{kg} \mathrm{q} .3 \mathrm{~d}$ ), vehicle, and the reference compound ENT (15 mg per kg q.d). Tumor growth and body weight were measured every 3 days using vernier calipers for the duration of the treatment. The volume was calculated as follows: tumor volume $=a \times b^{2} / 2$ ( $a$, long diameter; $b$, short diameter).

\section{Acknowledgements}

This work is financially supported by Hinova Pharmaceuticals Inc. and also partially supported by National Natural Science Foundation of China (No. 81472418, 81672951). We also thank the State Key Laboratory of Biotherapy and Cancer Center of Sichuan University for providing analytical service.

\section{References and notes}

1 Y. N. Wong, R. Ferraldeschi, G. Attard and J. de Bono, Nat. Rev. Clin. Oncol., 2014, 11, 365.

2 J. K. Rane, D. Pellacani and N. J. Maitland, Nat. Rev. Urol., 2012, 9, 595.

3 J. K. Myung, C. A. Banuelos, J. G. Fernandez, N. R. Mawji, J. Wang, A. H. Tien, Y. C. Yang, I. Tavakoli, S. Haile, K. Watt, I. J. McEwan, S. Plymate, R. J. Andersen and M. D. Sadar, J. Clin. Invest., 2013, 123, 2948.

4 L. Yin, Q. Hu and R. Hartmann, Int. J. Mol. Sci., 2013, 14, 13958.

5 T. M. Beer, A. J. Armstrong, D. E. Rathkopf, Y. Loriot, C. N. Sternberg, C. S. Higano, P. Iversen, S. Bhattacharya, J. Carles, S. Chowdhury, I. D. Davis, J. S. de Bono, C. P. Evans, K. Fizazi, A. M. Joshua, C. S. Kim, G. Kimura, P. Mainwaring, H. Mansbach, K. Miller, S. B. Noonberg, F. Perabo, D. Phung, F. Saad, H. I. Scher, M. E. Taplin, P. M. Venner, B. Tombal and P. Investigators, N. Engl. J. Med., 2014, 371, 424.

6 A. Parray, H. R. Siddique, S. Nanda, B. R. Konety and M. Saleem, Biol.: Targets Ther., 2012, 6, 267.

7 C. Helsen, T. Van den Broeck, A. Voet, S. Prekovic, H. Van Poppel, S. Joniau and F. Claessens, Endocr.-Relat. Cancer, 2014, 21, T105.

8 A. M. Moilanen, R. Riikonen, R. Oksala, L. Ravanti, E. Aho, G. Wohlfahrt, P. S. Nykanen, O. P. Tormakangas, J. J. Palvimo and P. J. Kallio, Sci. Rep., 2015, 5, 12007.
9 C. Tran, S. Ouk, N. J. Clegg, Y. Chen, P. A. Watson, V. Arora, J. Wongvipat, P. M. Smith-Jones, D. Yoo, A. Kwon, T. Wasielewska, D. Welsbie, C. D. Chen, C. S. Higano, T. M. Beer, D. T. Hung, H. I. Scher, M. E. Jung and C. L. Sawyers, Science, 2009, 324, 787.

10 Y. M. Ning, W. Pierce, V. E. Maher, S. Karuri, S. H. Tang, H. J. Chiu, T. Palmby, J. F. Zirkelbach, D. Marathe, N. Mehrotra, Q. Liu, D. Ghosh, C. L. Cottrell, J. Leighton, R. Sridhara, A. Ibrahim, R. Justice and R. Pazdur, Clin. Cancer Res., 2013, 19, 6067.

11 H. I. Scher, K. Fizazi, F. Saad, M. E. Taplin, C. N. Sternberg, K. Miller, R. de Wit, P. Mulders, K. N. Chi, N. D. Shore, A. J. Armstrong, T. W. Flaig, A. Flechon, P. Mainwaring, M. Fleming, J. D. Hainsworth, M. Hirmand, B. Selby, L. Seely, J. S. de Bono and AInvestigators, N. Engl. J. Med., 2012, 367, 1187.

12 M. Korpal, J. M. Korn, X. Gao, D. P. Rakiec, D. A. Ruddy, S. Doshi, J. Yuan, S. G. Kovats, S. Kim, V. G. Cooke, J. E. Monahan, F. Stegmeier, T. M. Roberts, W. R. Sellers, W. Zhou and P. Zhu, Cancer Discovery, 2013, 3, 1030.

13 W. C. Black, C. I. Bayly, D. E. Davis, S. Desmarais, J. P. Falgueyret, S. Leger, C. S. Li, F. Masse, D. J. McKay, J. T. Palmer, M. D. Percival, J. Robichaud, N. Tsou and R. Zamboni, Bioorg. Med. Chem. Lett., 2005, 15, 4741.

14 J. A. Gibbons, T. Ouatas, W. Krauwinkel, Y. Ohtsu, J. S. van der Walt, V. Beddo, M. de Vries and J. Mordenti, Clin. Pharmacokinet., 2015, 54, 1043.

15 J. Jiang, X. Pang, L. Li, X. Dai, X. Diao, X. Chen, D. Zhong, Y. Wang and Y. Chen, Drug Des., Dev. Ther., 2016, 10, 2181.

16 N. J. Clegg, J. Wongvipat, J. D. Joseph, C. Tran, S. Ouk, A. Dilhas, Y. Chen, K. Grillot, E. D. Bischoff, L. Cai, A. Aparicio, S. Dorow, V. Arora, G. Shao, J. Qian, H. Zhao, G. Yang, C. Cao, J. Sensintaffar, T. Wasielewska, M. R. Herbert, C. Bonnefous, B. Darimont, H. I. Scher, P. Smith-Jones, M. Klang, N. D. Smith, E. De Stanchina, N. Wu, O. Ouerfelli, P. J. Rix, R. A. Heyman, M. E. Jung, C. L. Sawyers and J. H. Hager, Cancer Res., 2012, 72, 1494.

17 H. Cheng, Y. Pei, F. Leng, J. Li, A. Liang, D. Zou, Y. Wu and Y. Wu, Tetrahedron Lett., 2013, 54, 4483.

18 N. D. Smith, C. Bonnefous and J. D. Julien, WO 2011103202A2, 2011.

19 M. D. Balabas, M. J. Evans, C. L. Sawyers, S. Yang, D. Hosfield and G. L. Greene, WO 2014066799A2, 2014.

20 Y. Chen and Y. Gong, WO 2014190895A1, 2014. 